\title{
APROXIMACIÓN A LA CRIMINALIDAD GALLEGA DE FINES DEL ANTIGUO RÉGIMEN
}

por

\author{
RAQUEL IGLESIAS ESTEPA
}

Universidade de Santiago de Compostela

RESUMEN: Este trabajo pretende conocer y caracterizar el patrón delictivo vigente en el Reino de Galicia y en la antigua provincia de Santiago a finales del Antiguo Régimen a través del análisis cuantitativo de la documentación judicial generada por el tribunal real entre 1700 y 1834. La interpretación de los datos obtenidos y de los cambios que en el devenir secular se producen en las tasas y la tipología de los delitos juzgados pasa por su contextualización en la realidad del momento, operación que ba puesto de manifiesto la estrecha relación existente entre el comportamiento criminal registrado y la coyuntura económica, social, demográfica, cultural e institucional gallega.

Palabras Clave: Pleitos. Criminalidad. Galicia. Antiguo Régimen.

ABSTRACT: . This work attempts to examine and characterise the criminal pattern prevailing in the Kingdom of Galicia and in the old province of Santiago at the end of the Old Regime through the quantitative analysis of the judicial documentation generated by the royal court between 1700 and 1834. The interpretation of this information, and the changing nature of fines and the typology of crimes brought to judgement, need to be placed in their proper context. This demonstrates the close links between the documented criminal behaviour and the economic, social, demographic, cultural and institutional circumstances of Galicia.

KEY WORDS: Lawsuits. Crime. Galicia. Old Regime.

\section{PROBLEMAS HeURISTICOS DEL ESTUDIO DEL CRIMEN}

El único medio que posibilita al historiador la observación de la criminalidad de la época pre-estadística es lo contencioso, esto es, el análisis de las materias que son objeto de demandas judiciales. Este fenómeno es visible a través de la documentación judicial de naturaleza penal, pero la utilización de esta fuente 
con el fin de estudiar la evolución de la delincuencia a lo largo de un período histórico determinado, presenta dos problemas insalvables:

1.- Los expedientes judiciales ofrecen una estadística de la criminalidad aparente puesto que sólo permiten el acceso a la historia de la justicia, es decir, a la actividad de las instituciones judiciales existentes en un determinado tiempo y espacio ${ }^{1}$. Como bien ha señalado Mario Sbriccoli, es necesario saber y no olvidar que los procesos tratan del crimen pero revelan la justicia ${ }^{2}$. Los números extraídos a partir de la documentación de un fondo criminal no cuantifican los delitos cometidos sino los perseguidos y por lo tanto no miden la presencia del crimen en un contexto espacio-temporal concreto sino el funcionamiento de la justicia dentro del mismo. El investigador debe de ser consciente de que uno de los sesgos esenciales de la documentación judicial es el hecho de que ésta es el resultado de un proceso de selección y filtración y de que en realidad, la documentación generada por los tribunales no es más que la punta del iceberg de la justicia en el Antiguo Régimen. Así, para que un hecho delictivo del pasado pueda ser tratado estadísticamente por el historiador actual son necesarias dos condiciones: que el sistema penal vigente en la época lo conozca y que acepte hacerse cargo de él ${ }^{3}$. Sin embargo, muchos de los crímenes no eran detectados por la institución judicial sino que se resolvían recurriendo a vías alternativas no oficiales (acuerdos, arbitrajes intracomunitarios, etc.); otros sí eran conocidos pero no pasaban de la fase inicial del juicio por las reticencias de la víctima a continuarlo debido a diversos motivos (costes demasiado elevados para su economía, necesidad de emplear un tiempo del que no dispone, consideración de que las penas a aplicar eran excesivas para el delito cometido, etc.); otras veces era el propio magistrado el que decidía abandonar su conocimiento en la fase de información por falta de pruebas. Por lo tanto, los casos que llegan a los tribunales son el producto final de un proceso de selección y el resultado de interacciones entre víctima, ofensor, comunidad y autoridades ${ }^{4}$. A ello hay que añadir el sempiterno problema de la desaparición de documentación de numerosos depósitos judiciales, lo que se debe tanto a una «selección natural» de los documentos a consecuencia de su destrucción y deterioro por agentes naturales comunes a todos los archivos, como a una «selección voluntaria», producto de los expurgos tan característicos del siglo XIX y que respondieron tanto a las

\footnotetext{
1 Bercé, Y-M. y SOMAN, A., "Les archives du Parlament dans I'Histoire» en Bibliothèque de l'Ecole des Chartes, $\mathrm{n}^{\circ} 153,1995$, pp. 255-273.

2 SBricCol, $M$, «Fonti giudiziarie e fonti giuridiche. Riflessioni sulla fase attuale degli studi di storia del crimine e della giustizia criminale», en Studi Storici, 1988/2, p. 494.

3 BASSETTE, J-M., "La fabrication du criminel: entre contingences de carrière et réaction sociale», en GARnOt, B. (dir.), De la déviance à la délinquance, XV-XXe siècles, Dijon, 1999, p. 135.

4 BEATTIE, J.M., "Judicial records and the measurement of crime in Eighteenth-century England» en KNAFLA, L.A. (ed.) Crime and criminal justice in Europe and Canada, Ontario, 1985, pp. $127-145$.
} 
necesidades de papel y de espacio como al deseo de liberarse de la memoria colectiva.

2.- Dado que la documentación utilizada procede directamente de los tribunales (causas criminales), el estudio de la evolución de los comportamientos delictivos en un contexto espacio-temporal concreto se enfrenta con un problema prácticamente irresoluble: saber si los cambios detectados en los niveles de la delincuencia a lo largo del tiempo reflejan mutaciones reales en la criminalidad o simplemente alteraciones en la eficacia de la administración de justicia y en las preocupaciones de las autoridades. En este sentido, las transformaciones en la jurisdicción entre los distintos juzgados y organismos encargados de la represión del crimen, la adopción de medidas más eficaces, las variaciones en la definición legislativa de las infracciones al igual que las modificaciones en las actitudes de las autoridades podían influir en el número y tipo de ofensas que llegaban a ser tratadas por la justicia. Por un lado, el establecimiento de tribunales de excepción para el tratamiento de determinados delitos y/o delincuentes, como es el caso de los juzgados de los Prévots y de los Présidiaux en Francia en lo que atañe a la delincuencia habitual de los grupos desarraigados y marginados caracterizados por su movilidad y rechazo a las normas de vida de la comunidad', así como la creación de nuevas instituciones preventivas y/o represivas, como por ejemplo la Comisión de Vagos en tiempos de Carlos III con el fin de vigilar y reprimir los cada vez más voluminosos contingentes de población inestable o desocupada ${ }^{6}$, sustrajeron a las instancias de justicia tradicionales el conocimiento de una parte de los delitos. Por otro lado, la mayor o menor preocupación de los jueces y legisladores por castigar ciertos crímenes es un factor determinante para explicar su presencia o ausencia en los fondos judiciales generados en un período concreto. Tal vez el ejemplo más claro a este respecto sea la desaparición de los procesos por brujería de los archivos de los tribunales franceses, ingleses y españoles a fines del siglo XVII como consecuencia del desinterés demostrado por los magistrados reales hacia las denuncias de la población, pues en dicha centuria éstos dejan de ver la brujería como una actividad de gran peligro para la sociedad para considerarla un simple fruto de la superstición ${ }^{7}$. En este mismo orden de cosas, el aumento de las acusa-

5 CASTAN, N.: «La justice expéditive», en Annales E.S.C., año 31, n²2, 1976, p. 332.

6 HeRnandez SANCHEZ, F.: “La corte envidiable": delincuencia y represión en el Madrid de Carlos III (1759-1788)», en Carlos III, Madrid y la Ilustración, Madrid, 1988, p. 340. En el caso de París el establecimiento de la institución policial explica la disminución de las denuncias judiciales referidas a violencias de obra y palabra puesto que los actos que no atentan contra la propiedad ni el orden público son tratados ahora en las comisarías de policía y casi nunca llegan a suscitar procesos judiciales. FARGE, A. y ZYSBERG, A.: «Les théatres de la violence à Paris au XVIIIe siècle», en $A n$ nales E.S.C., 34 année, 1979, pp. 985 y 986.

7 Soman, A.: «La décriminalisation de la sorcellerie en France», en Histoire, Economie et Société, $\mathrm{n}^{\circ} 2$, 1985, pp. 179-203; «Sorcillerie, justice-criminel et société dans la France Moderne ( l'ego- $^{\prime}$ histoire d'un Américain à Paris)» en Histoire, Economie et Société, 1993/2, pp. 177-217 y SHARPE, 
ciones por robo y la paralela disminución de las relativas a la violencia física y verbal en la segunda mitad del setecientos es explicada hoy en día por buena parte de los especialistas del crimen atendiendo a la mayor preocupación de los legisladores y jueces del momento por proteger los bienes.

Las deficiencias de la documentación judicial como fuente para la cuantificación del crimen, han llevado a algunos investigadores a criticarla duramente. Así, en opinión de Lawrence Stone, la documentación de los tribunales es un indicador poco fiable de la criminalidad ya que tiene escasa relación con el número real de los delitos, la cantidad de casos tratados en los juzgados de la Edad Moderna es pequeña y, además, es cuestionable el hecho de cuantificar la delincuencia cuando la cuantificación de la población para la época objeto de examen es muy incierta. La solución que propone es el abandono completo de las tasas y la concentración en el análisis de los casos típicos del período, lo que provocó criticas inmediatas. En 1981, P. C. Hoffer publica un artículo9 en el que revisa e invalida esta propuesta atendiendo a la imposibilidad de definir lo "típico» de una época sin ningún tipo de medida sobre las tendencias de las diferentes clases de comportamientos delictivos y a que Stone no había determinado qué consideraba como poco numeroso. Además, a su entender, aún aceptando que los registros judiciales no dan cuenta fielmente de la delincuencia real, las mutaciones en las ofensas juzgadas reflejan alguna combinación de cambio en el comportamiento criminal y en la represión.

La tesis de que las estadísticas criminales realizadas a partir de la documentación judicial son consecuencia sobre todo de las transformaciones en el sistema represivo y en las actitudes de los grupos dirigentes con respecto a los fenómenos de desviación ${ }^{10}$, es la hoy en día admitida por la mayor parte de los investigadores, quienes consideran que tal deficiencia no es óbice para que los datos obtenidos sirvan como indicador aproximado de las infracciones cometidas ${ }^{11}$. Los registros judiciales no nos permiten establecer el número exacto de

J.A.: «Criminalization, decriminalization and elite attitudes to witchcraft in England c.1563-1736: a preliminary survey", en I.A.H.C.C.J. Bulletin, $\mathrm{n}^{\circ} 17,1992 / 93$, pp. 15-28.

8 El siglo XVIII es testigo de un fuerte endurecimiento de las leyes sobre el robo y el bandolerismo en países como Inglaterra y España, en donde la legislación afectó de forma especial a la ciudad de Madrid. HAY, D.: «Property, authority and the Criminal Law» en Albion's fatal tree: crime and society in Eighteenth-century England, Londres, 1975, pp.20-24 y ALLOZA APARICIO, A.: "Crime and social change in Eigteenth-century Madrid», en I.A.H.C.C.J. Bulletin, ${ }^{\circ}{ }^{\circ}$, 1994, p. 17.

9 HOFFER, P. C.: «Counting crime in premodern England and America. A review essay», en Historical Methods, vol.14, $\mathrm{n}^{\circ} 4,1981$, pp. 187-193. Nuestro conocimiento de la postura de $\mathrm{L}$. Stone se debe a este mismo trabajo al habernos resultado imposible acceder al artículo que en 1980 publicó en la colección New York Review of Books.

10 GARNOT, B.: «Une illusion historiographique: justice et criminalité au XVIIIe siècle», en Revue Historique, $\mathrm{n}^{\circ} 570,1989$, pp. 361-379.

1 LeVy, R. y ROBERT, Ph.: «La sociologie et l'histoire pénale» en Annales E.S.C., 1984, n²2, pp.400-422 y SHARPE, J.A.: "Quantification and the history of crime in Early Modern England: problems and results» en Historial Social Research, vol. 15, n4, 1990, p. 23.

Hispania, LXV/2, núm. 220 (2005) 409-442 
ofensas, pero está fuera de toda duda que el crimen registrado en ellos supone algo más que casos inusuales objeto de interés por parte de los sectores sociales en el poder; representan en cierta medida la serie de delitos, víctimas y agresores, por lo que la documentación de los archivos criminales es significativa ${ }^{12}$. Aún admitiendo que los cambios en el número de acusaciones se derivan de modificaciones en el nivel y la eficacia de las persecuciones, lo cierto es que éstos también deben de estar condicionados de algún modo por la aparición de nuevos crímenes y por un correspondiente crecimiento de comportamientos desviados ya existentes y que ahora interesan más a las autoridades. Por lo tanto, tal y como indica Victor Bayley, las dos ópticas existentes a la hora de considerar las imputaciones de delito, es decir, entenderlas como un indicador de los cambios sucedidos en la larga duración en el comportamiento criminal o como un indicador de mutaciones en el sistema judicial, no son incompatibles entre $s^{13}$.

En cualquier caso, las insuficiencias y lagunas de las fuentes disponibles para el análisis de la criminalidad no son lo bastante graves como para impedir que la cuantificación de la información contenida en ellas sirva como indicador aproximado de las infracciones cometidas y de su modificación en el transcurrir del tiempo, sobre todo cuando el marco temporal de referencia es de corta o media duración. En general, se puede considerar que los cambios en el plano administrativo no fueron lo suficientemente masivos ni repentinos como para llegar a invalidar la muestra del crimen representada en los procesos judiciales ${ }^{14}$. Además, si bien es cierto que la documentación refleja sobre todo las mutaciones en la disposición de los grupos dirigentes con respecto a los fenómenos de desviación, no hay que olvidar que también dan cuenta de las variaciones en la actitud de la comunidad hacia la justicia y el crimen, pues la postura adoptada por ésta respecto de las instancias oficiales de justicia o de determinadas ofensas permiten explicar el aumento o descenso de los niveles de criminalidad general o de un delito en particular en las estadísticas elaboradas a partir de los datos judiciales. En este sentido, recordemos que a lo largo del Antiguo Régimen se detecta una menor reticencia de la población en lo que atañe a la utilización de los tribunales como instrumento para solucionar sus conflictos ${ }^{15}$, lo que conlleva un aumento de la cantidad global de causas. Pero además, se ha constatado que ciertas transformaciones en la mentalidad popular repercuten en la mayor o menor denuncia de crímenes concretos y así, el cambio experi-

12 BeAtTiE, J.M.: «Judicial records and the measurement of crime...», opus. cit., p. 138.

13 BAILEY, V.: «Reato, giustizia penale e autorità in Inghilterra. Un decennio di studi storici, 1969-1979", en Quaderni Storici, n²44, 1980, pp. 581-602.

14 Las transformaciones en la jurisdicción entre los distintos tribunales y en los niveles de administración en la corta y media duración no fueron lo suficientemente amplias y rápidas como para distorsionar los indicadores de forma relevante BEATTIE, J.M.: «The pattern of crime in England 1660-1800", en Past and Present, $\mathrm{n}^{\circ}$ 62, 1974, p. 57.

15 IGLESIAS ESTEPA, R.: Las quiebras del orden cotidiano: comportamientos criminales en la sociedad gallega de fines del Antiguo Régimen, Santiago de Compostela, 2004, pp. 104-106.

Hispania, LXV/2, núm. 220 (2005) 409-442 
mentado por ésta a finales del siglo XVIII en el sentido de una mayor tolerancia en lo que concierne a los comportamientos sexuales desviados de la norma fijada por la Iglesia, explica la caída del número de denuncias de ruptura de palabra de matrimonio en los tribunales gallegos ${ }^{16}$.

Nuestra investigación contempla dos niveles diferentes de análisis desde el punto de vista geográfico.

1.- En primer lugar, estudiaremos la criminalidad registrada en el conjunto del Reino de Galicia a partir de los datos contenidos en varias matrículas enviadas por la sala del crimen de la Real Audiencia al Consejo de Castilla en los años finales del siglo XVIII con el objetivo de informar sobre las causas vistas y pendientes en ella, bien por conocimiento propio, bien porque le habían sido remitidas en apelación o consulta por las justicias inferiores. A ello hay que añadir la información de la estadística criminal que para cada una de las cuatro provincias gallegas realiza Pascual Madoz en 1848.

2.- El segundo lugar, examinaremos la criminalidad de la antigua provincia de Santiago, la cual, al ser la mayor de las siete provincias gallegas en cuanto a población, permite conocer el patrón criminal que caracteriza a cerca del $30 \%$ de los gallegos de la época, siendo además la más representativa de las provincias atlánticas del Reino.

\section{LA CRIMINALIDAD EN EL REINO DE GALICIA}

El ingente volumen de procesos que llegaron a conocimiento de la Real Audiencia de Galicia a lo largo de su existencia como tribunal supremo del Reino parece corroborar la imagen de sociedad extremadamente conflictiva y litigante ofrecida por algunos contemporáneos. En opinión del ilustrado Francisco Somoza de Mosoriu, la plaga de los litigios era uno de los mayores estorbos para el desarrollo de la riqueza e industria gallega ${ }^{17}$, mientras que el Regente don Felipe Díaz de Quejada justificaba en 1787 el gran número de pleitos que anualmente estaban pendientes en el tribunal regio atendiendo a que la cavilación, rencor y deseo de venganza a que son inclinados estos naturales provocaba que la acumulación de trabajo fuese superior a la de cualquier otro tribunal pues en este país, por pequeña que sea la cuestión de injurias, reales o verbales, nunca se cesa hasta llegar a la sala del crimen ${ }^{18}$. Sesenta años más tarde, el supuesto espíritu

16 GonZález FernÁNDEZ, J.M.: ««Amancebados y maldivertidos» en la Galicia rural del siglo XVIII. La labor de la justicia ordinaria local en la represión de los comportamientos sexuales heterodoxos (I)», en Pontevedra. Revista de Estudios Provinciais, ${ }^{\circ}$ 12, 1996, p. 238.

17 SOMOZA DE MONSORIU, F.: Estorvos $i$ remedios de la riqueza de Galicia. Discurso político-legal, Santiago de Compostela, 1775, p.29.

18 Carta enviada por el Regente de la Real Audiencia de Galicia en mayo de 1787 a Floridablanca y reproducida en parte por Antonio RISCO en su artículo "Comunidades territoriales y

Hispania, LXV/2, núm. 220 (2005) 409-442 
rencoroso y vengativo de los gallegos continúa siendo el argumento justificativo del elevado número de delitos y delincuentes constatado en Galicia y así, en el análisis que a mediados del siglo XIX realiza Pascual Madoz sobre la moralidad de los pueblos a través de los registros de las distintas Audiencias territoriales españolas, el autor señala que los habitantes del noroeste peninsular son vengativos, y es tan viva en ellos esta pasión que cualquiera que les hace una ofensa puede contar con que adonde quiera que se dirija, lleva sobre su cabeza la eterna venganza del agraviado ó de sus parientes ${ }^{19}$, a lo que añade su inclinación a la bebida y a los enfrentamientos de índole pasional ${ }^{20}$.

Los análisis que sobre la conflictividad criminal llevaron a cabo los coetáneos sirven de punto de partida al historiador actual, quien se plantea como primer objetivo el estudio estadístico de la criminalidad juzgada en aras de confirmar o refutar esa supuesta tendencia de los gallegos a delinquir y litigar, para pasar después a interpretar los resultados mediante su contextualización en la realidad económica, social, demográfica, cultural e institucional del momento. Ahora bien, la investigación cuantitativa del crimen en la Galicia de fines del Antiguo Régimen resulta especialmente difícil puesto que obliga a emprender la ardua tarea de vaciar, si no las causas conservadas en los fondos judiciales de la Real Audiencia, sí al menos sus fichas, siguiendo un método que permita conocer la delincuencia reprimida en todo el Reino así como definir los posibles modelos criminales y observar sus mutaciones en el transcurso del tiempo. Debido a la enorme cantidad de procesos conservados, esta labor tiene que ser necesariamente abordada por un equipo de investigadores, de manera que la única posibilidad para el historiador aislado de aproximarse a la criminalidad del Reino de Galicia en la época que nos ocupa es la cuantificación de los datos contenidos en las matrículas de causas que la sala del crimen remitió al Consejo de Castilla en los años finales del siglo XVIII, operación que para el conjunto de las Audiencias y Chancillerías españolas ha realizado José Miguel Palop Ramos a partir de los informes correspondientes a los años 1786 y $1788^{21}$.

Para fines del setecientos sólo hemos logrado localizar cuatro de las matrículas de litigios sustanciados y pendientes en la Real Audiencia, las cuales, en ningún caso comprenden anualidades completas. Los dos primeros informes se

\footnotetext{
marginalidad: Galicia en las relaciones de causas pendientes», Anales de la Uniersidad de Alicante, $\mathrm{n}^{\circ} 18,2000, \mathrm{p} .398$.

19 MADOZ, P.: Diccionario geográfico-estadístico-bistórico de España y sus posesiones de Ultramar, Madrid, 1850, vol.II, p. 353.

20 «Influye asimismo no poco en las contiendas y quimeras de los habitantes de este territorio, el escesivo uso del vino, y las filazones o reuniones nocturnas de las jóvenes para hilar y hacer otras labores, á las cuales concurre el otro sexo, de donde provienen repetidas contiendas de zelos, á que propenden mucho los gallegos». MADOZ, P.: Diccionario geográfico..., opus.cit., vol.II, p. 353.

21 Palor Ramos, J-M.: «Delitos y penas en la España del siglo XVIII», en Estudis, n²2, 1996, pp.65-103 y «Notas sobre la criminalidad en Galicia a finales del siglo XVIII» en Conflictos $y$ represiones en el Antiguo Régimen, Universidad de Valencia, 2000, pp. 181-208.
} 
conservan en el Archivo Histórico Nacional ${ }^{22}$ y se refieren respectivamente al primer semestre del año 1786 y del año 1788. En ellos, los escribanos de la sala del crimen recogen la información por mensualidades, lo que hace que muchas de las querellas se repitan a lo largo de meses consecutivos mientras que otras, las menos, van desapareciendo progresivamente una vez concluidas. Las pleitos se distribuyen en cinco bloques según su tema general: «sobre muertes», «sobre robos», "sobre malos tratamientos», "sobre amancebamientos» y «sobre causas comunes», epígrafe que también es denominado «sobre diferentes delitos». Las otras dos matrículas han sido halladas en la serie Régimen Interno de la Real Audiencia de Galicia y hacen referencia a los casos vistos en la sala durante los meses de octubre, noviembre y diciembre de $1794^{23}$ y entre enero y junio de $1795^{24}$. En esta ocasión los procesos de naturaleza penal no se agrupan por meses sino por trimestres y su subdivisión responde al criterio de su situación procesal, distinguiéndose entre causas providenciadas, pendientes y retenidas.

A pesar de las importantes limitaciones que presenta toda esta documentación al ceñirse a momentos muy concretos del siglo XVIII y ni siquiera ofrecer información completa de todo un año, no hay duda de que la actividad judicial de la Real Audiencia como tribunal de primera instancia, apelación y consulta, refleja de forma aproximada el panorama criminal gallego de los años finales de la Edad Moderna, el cual puede ser contrastado con la estadística criminal que a partir de los datos de las demandas sustanciadas en la Audiencia Territorial durante el año 1848 elabora Pascual Madoz en su Diccionario Geográficoestadístico-histórico de España ${ }^{25}$

La comparación de la imagen que de la criminalidad obtenemos a partir de la utilización de ambas fuentes pasa irremediablemente por la unificación de los términos de análisis. En este sentido, aunque el sistema de organización de la información en cada una de ellas responde a criterios diferentes, lo cierto es que sus datos son homologables, lo que hace posible la creación de una estadística propia con todos ellos. El criterio que hemos seguido ha sido el mismo que el empleado por los escribanos de la sala del crimen en 1786 y 1788 , de modo que la unidad de recuento son las causas (salvo en el año 1848 puesto que Madoz contabiliza los delitos) mientras que la clasificación se ha realizado atendiendo a las cinco grandes categorías delictivas por ellos identificadas. En consecuencia, hemos eliminado de la muestra los expedientes que se iban repitiendo de un mes a otro al tiempo que hemos integrado en alguno de esos diferentes epígrafes los crímenes registrados en los años 1794 y 1795 así como en la estadística del Diccionario geográfico-estadístico, excluyendo aquellos en los que no se especificaba el tema. La lectura de los informes remitidos al Consejo

22 A.H.N., Consejo de Castilla, leg. 6.159.

23 A.R.G., Régimen Interno, leg. 29.212 nº155, 156 y 157.

24 A.R.G., Régimen Interno, leg. $29.219 \mathrm{n}^{\circ} \mathrm{6}$.

25 MADOZ, P.: Diccionario geográfico-estadístico..., opus.cit., vol.II, p. 351.

Hispania, LXV/2, núm. 220 (2005) 409-442 
de Castilla revela que los pleitos por «malos tratamientos» incluyen tanto denuncias de golpes y heridas como de injurias e insultos, de manera que dentro de esta categoría hemos integrado todos los procesos que por tales asuntos se contenían en las matrículas de 1794 y 1795 así como los datos correspondientes a los epígrafes «heridas y contusiones», "golpes y malos tratamientos» e «injurias verbales» de la estadística de Madoz. En cuanto al título «amancebamiento", recoge en realidad diversos comportamientos considerados desviados en materia sexual tales como el trato ilícito, el adulterio, los embarazos ilegítimos, el escándalo, etc., de forma que en este campo hemos agrupado los casos relativos a la moral sexual, lo que, en el cuadro de delitos tratados en la Audiencia Territorial se recoge en las casillas «inmoralidad y escándalo», «adulterio» y «estupro». Finalmente, el cajón de sastre de «causas comunes» o «diferentes delitos» hace referencia fundamentalmente a los excesos cometidos por los oficiales de la justicia, resistencia a la autoridad, fugas de reos, uso de armas prohibidas y a lo que generalmente se conocía como «mala conducta», todo lo cual se distribuye en el Diccionario entre las categorías de «resistencia y desobediencia a las autoridades», "escesos y faltas de los empleados en el ejercicio de sus funciones», "fuga de presos y presidiarios», «vagancia y mala conducta» y «aprehensión y uso de armas prohibidas».

La tabla I sintetiza los datos absolutos y porcentuales que sobre las cinco categorías delictivas diferenciadas se contienen en las cuatro matrículas de causas y la estadística criminal de Madoz. La inexistencia de factores explicativos externos hace suponer que las variaciones en el número total de querellas que llegan a ser conocidas por el tribunal supremo del Reino en años tan próximos entre sí (187 en 1786, 287 en 1788, 50 en 1794 y 77 en el año 1795) son una consecuencia directa de las lagunas de la documentación. En cuanto a lo elevado de la cifra global correspondiente al año 1848, se explicaría atendiendo a que la unidad de recuento empleada es el número de delitos, el cual suele ser superior al de procesos debido a que en uno de éstos puede ser juzgado más de un crimen, y a que el período de referencia es toda una anualidad frente a los seis meses en que se fundamentan las muestras de los años 1786, 1788 y 1795 y el trimestre que sirve de base a los datos del año 1794. Por otra parte, es necesario tener en cuenta que la población de mediados del siglo XIX recurriría a los tribunales de justicia en mayor medida de lo que lo hacía la de finales del XVIII y, finalmente, que la reforma del organigrama de administración de justicia por parte del nuevo gobierno liberal habría redundado en una mayor eficacia en la persecución y represión de la delincuencia. 
TABla I. DistribuCión DE LA CRIMINALIDAD EN GALICIA SEGÚN EL TIPO DE DELITO JUZGADO.

\begin{tabular}{|l|c|c|c|c|}
\hline Grupo Delictivo & \multicolumn{2}{|c|}{$1786-1795$} & \multicolumn{2}{c|}{1848} \\
\hline & Número & $\%$ & Número & $\%$ \\
\hline Muertes & 197 & 32,78 & 182 & 9,47 \\
\hline Robos & 144 & 23,96 & 777 & 40,43 \\
\hline Maltrato & 131 & 21,80 & 679 & 35,33 \\
\hline Amancebamientos & 68 & 11,34 & 21 & 1,10 \\
\hline Causas Comunes & 61 & 10,15 & 263 & 13,68 \\
\hline Total & 601 & 100 & 1922 & 100 \\
\hline
\end{tabular}

Observamos que los atentados contra la persona, agrupados bajo las categorías de muertes y maltrato, son mayoritarios, suponiendo el $54,58 \%$ del total de litigios en la muestra 1786/1795. En dicho período, las demandas por robo ocupan el segundo puesto en el ranking de la criminalidad reprimida, a gran distancia de las anteriores, puesto que representan el 23,96\% del total de causas vistas en el tribunal superior del Reino. Será en la primera mitad del siglo XIX cuando se produzca el despegue de las ofensas contra la propiedad, situándose éstas casi en pie de igualdad respecto de las acciones que tienen por objeto la integridad física del individuo o su honor $(40,43 \%$ frente a $44,8 \%)$, las cuales han descendido diez puntos en el curso aproximado de medio siglo.

En el epígrafe de los delitos contra la persona, las querellas por muerte contabilizadas en las matrículas entre los años 1786 y 1795 son muy superiores a las de malos tratos de obra y palabra, lo que se adecua al perfil global que el resto de audiencias y chancillerías españolas dibujan durante el período final del XVIII ${ }^{26}$. El análisis comparativo de las tasas de homicidio constatadas en los últimos años del setecientos y la que resulta para 1848 revela una abrupta caída de éstos (del $32,78 \%$ al 9,47\%), lo que concuerda con la tantas veces confirmada tendencia de su progresivo declive secular ${ }^{27}$ y que inicialmente fue

26 Los homicidios suelen suponer más de la mitad del apartado de delitos contra la persona. PALOP RAMOS, J-M.: «Delitos y penas en la España del siglo XVIII», opus.cit., p. 83.

27 Los especialistas en la historia de la criminalidad asumen que el homicidio es el crimen violento mejor registrado en los archivos judiciales tanto porque resultó difícil de ocultar como porque suscitó constantemente la repulsión popular y por lo tanto su denuncia. Su análisis continuado a partir de datos estadísticos (número de homicidios por cada 100.000 habitantes) llevó al sociólogo Tedd Gurr a postular la teoría del declive de la violencia interpersonal desde la Edad Media hasta el siglo XIX en razón de una progresiva sensibilidad de la población de cara a la violencia. GURR, T.R.: «Historical trends in violent crime: a critical review of the evidence», en Crime and Justice. An Annual Review of Research, n³, 1981, p. 306 y ss. También Lawrence Stone, empleando los datos del propio Gurr y de otros autores, confirmó, en los inicios de la década de los ochenta, la teoría de la tendencia general a la baja de las tasas de homicidio desde el siglo XIII hasta la actualidad en Inglaterra. STONE, L.: «Interpersonal violence in English society, 1300-1980», en Past and Present, $\mathrm{n}^{\circ} 101,1983$, pp. $22-33$. Esta misma tendencia ha sido constatada posteriormente para la mayoría

Hispania, LXV/2, núm. 220 (2005) 409-442 
vista como una prueba irrefutable de la decadencia de la violencia interpersonal. Sin embargo, estudios posteriores han precisado que las tasas de homicidio no pueden ser consideradas como una medida fidedigna del nivel global de la violencia en una sociedad determinada puesto que no existe una relación proporcional entre las muertes y el resto de las manifestaciones de violencia contra el individuo $^{28}$. Así, en el caso gallego observamos que a mediados del siglo XIX, a pesar de la caída en picado del porcentaje de procesos por muerte, las ofensas contra la persona se siguen manteniendo a la cabeza de la jerarquía criminal, representando el $44,8 \%$ del total, si bien ahora su cuota es inferior a la media general precedente, la cual hemos visto que se situaba en torno al $54,6 \%$. Esto es así, porque el descenso en el número de causas por homicidio no se vio acompañado de un paralelo declive de las suscitadas por injurias y lesiones; al contrario, éstas no sólo aumentan en términos absolutos sino que también crece su peso específico dentro del grupo delictivo al que pertenecen (los malos tratos representan ahora el $78,86 \%$, de los atentados contra la persona), lo que conlleva la inversión de la tendencia vista en los años finales de la pasada centuria ${ }^{29}$.

Por su parte, la denuncia y persecución de los delitos contra la moral sexual en Galicia todavía sigue siendo relevante en el siglo XVIII, época en la que su represión está sufriendo un retroceso general en el conjunto de España. Tal es así que, sin llegar a los extremos de la audiencia canaria, en donde los amancebamientos, adulterios, etc. suponen el $40,7 \%$ del total de demandas ${ }^{30}$, Galicia, con su $11,34 \%$, presenta unas tasas muy superiores a las de la gran mayoría de los tribunales regios de jurisdicción superior ${ }^{31}$ y bastante similares a las constatadas en las audiencias de Mallorca $(13,1 \%)$, Sevilla $(10,9 \%)$ y Cataluña $(8,9 \%)$. En opinión del Regente Díaz de Quejada, la inmoralidad sexual de los gallegos se derivaba de las condiciones materiales de vida y vivienda propias

de los países europeos, Rousseaux, X.: «Ordre moral, justice et violence: 1 ' homicide dans les sociétés européenes. XIIIe-XVIIIe siècle», en GARNOT, B. (dir.), Ordre moral et délinquance de l'Antiquité au XXe siècle, Dijon, 1994, pp. 65-82 y se ha explicado normalmente dentro del cuadro teórico de la civilización de las costumbres o de la modernización de la sociedad SPIERENBURG, P.: «Violence and the civilizing process: does it works?» en Crime, Histoire et Sociétés, 2001, vol.5 no 2, pp. 87-105 y THOME, H., "Modernization and crime: What is the explanation?", en I.A.H.C.C.J. Bulletin, $\mathrm{n}^{\circ}$ 20, 1995, pp. 31-48 y «Explaining long term trends in violent crimes», en Crime, Histoire et Sociétés, 2001, vol. $5 \mathrm{n}^{\circ} 2$, pp. 69-86.

28 CocKBuRN, J.S.: «Patterns of violence in English society: homicide in Kent, 1560-1985», Past and Present, $n^{\circ} 130,1991$, p. 103.

29 En el conjunto español de fines del XVIII, los malos tratos representaban el 44,58\% de los atentados contra la persona y el $15,88 \%$ del total de delitos reprimidos por la justicia. PALOP RAMOS, J.M.: «Delitos y penas en la España del siglo XVIII», opus.cit., p. 67.

30 PALOP RAMOS, J-M.: «Notas sobre la criminalidad en Canarias durante el siglo XVIII» en Homenaje a Antonio de Bethencourt Massieu, Las Palmas de Gran Canaria, 1995, vol.III, p. 21.

31 Las tasas de delitos contra la moral sexual pública en las audiencias españolas son: $5,5 \%$ en la Chancillería de Granada, 6,7\% en la de Valladolid, 1,6\% en la audiencia de Valencia, 5,4\% en Navarra y 5,2\% en Aragón. PALOP RAMOS, J-M.: «Delitos y penas en la España...», opus.cit, p. 71 y ss. 
del hábitat rural, las cuales fomentaban la promiscuidad y propiciaban la relajación de costumbres ${ }^{32}$. Al igual que en el caso de los ataques a la propiedad, la transformación de la criminalidad de naturaleza sexual parece no haber tenido lugar hasta bien entrado el siglo XIX, cuando su proporción llega al mínimo del $1,10 \%$.

El incontestable protagonismo de la violencia en el conjunto de la criminalidad del Reino de Galicia a fines del Antiguo Régimen y el lugar secundario que en ella ocupan los atentados contra el patrimonio $(23,96 \%)$ hacen que éste se inscriba plenamente en el modelo delictivo propio de las sociedades todavía no inmersas en el proceso económico y social de carácter industrial. En este sentido, el patrón criminal constatado en Galicia a finales del siglo XVIII es semejante al que en esta misma época se detecta en las audiencias de Valencia, Navarra y Aragón, en donde homicidios, lesiones e injurias son claramente superiores a robos y daños, al tiempo que difiere del verificado en los tribunales reales de Cataluña, Valladolid y Sevilla, en los que las expresiones criminales que tienen por objeto la sustracción y destrucción de la propiedad son mayoritarios $^{33}$. El carácter tradicional del paradigma gallego se vería confirmado también en la todavía significativa represión de los comportamientos contrarios a la moral, desempeñando el Estado la importante tarea de defensa de la religión a través del castigo de toda una serie de transgresiones que tienen tanto de delitos como de pecados ${ }^{34}$.

El notable ascenso experimentado por los hurtos a lo largo de la primera mitad del XIX, teóricamente permite confirmar en Galicia una evolución de la violencia al robo en la línea de los trabajos impulsados por Pierre Chaunu y la Escuela de Normandía en los años sesenta del siglo $\mathrm{XX}^{35}$, lo que, combinado con el paralelo descenso de la represión dirigida contra el comportamiento sexual inmoral marcaría el paso a una nueva época criminal. Sin embargo, la

32 RISCO, A.: «Comunidades territoriales y marginalidad...», opus.cit., p. 403.

33 En Aragón la tasa de delitos contra la persona ascendía al $47 \%$ y la de atentados contra la propiedad se reducía al $14 \%$. En Navarra las proporciones eran del $34 \%$ y el $15 \%$ respectivamente y en Valencia del $51 \%$ y el $38 \%$. Frente a ellas, Cataluña, con un $37 \%$ de ataques al patrimonio y un $30 \%$ de agresiones a la persona, Valladolid, con un $40 \%$ y un $35 \%$ respectivamente, y, en mayor medida, Sevilla, en donde los robos casi duplican a lesiones, homicidios e injurias (40\%/23\%), serían zonas criminalmente más avanzadas. PALOP RAMOS, J-M.: «Delitos y penas en la España del siglo XVIII», opus.cit., p. 71 y ss.

34 TOMÁS Y VALIENTE, F., "Delincuentes y pecadores", en Sexo barroco y otras transgresiones premodernas, Madrid, 1990, pp. 11-31.

35 Boutelet, B.: «Etude par sondage de la criminalité dans le bailliage du Pont-de-L' Arche (XVIIe-XVIIIe siècles). De la violence au vol en marche vers l'escroquerie» en Annales de Normandie, $\mathrm{n}^{\circ} 12,1962$, pp. 235-262; GECOT, J-C., «Etude par sondage de la criminalité dans le bailliage de Falaise(XVII-XVIIIe siècle). Criminalité diffuse ou société criminelle?» en Annales de Normandie, $\mathrm{n}^{\circ} 16$, 1966, pp. 103-164. Una síntesis de los principales postulados de la escuela de Normandía la ofrece Emmanuele LE ROY LADURIE en "La décroissance du crime au XVIIIe siècle: bilan d'historiens» en Contrepoint, $\mathrm{n}^{\circ}$ 9, enero 1973, pp. 227-237.

Hispania, LXV/2, núm. 220 (2005) 409-442 
realidad del panorama delictivo gallego es más compleja de lo que cabría suponer a partir de esta primera imagen general de predominio de la violencia interpersonal, progresivo avance de los atentados contra la propiedad en el siglo XIX y pérdida de importancia de los delitos de índole sexual. El modelo criminal del Reino combina ya en el siglo XVIII rasgos arcaicos con otros que apuntan hacia la modernidad, pero esto sólo es visible a través del análisis diacrónico y comparativo de la criminalidad rural y urbana durante el setecientos y la primera mitad del ochocientos, algo que los datos generales que para Galicia ofrecen los informes de causas aquí empleados no permiten, pero que sí podremos realizar al estudiar la delincuencia en la antigua provincia de Santiago.

Lo que sí permiten las matrículas es examinar la distribución geográfica de los litigios criminales conocidos por la Real Audiencia, lo que indirectamente nos ofrece la posibilidad de conocer qué áreas están más o menos criminalizadas así como comprobar en qué medida este esquema general de la delincuencia gallega que acabamos de definir se ajusta a las distintas provincias del Reino. Para ello, hemos procedido a la agrupación, siguiendo el criterio provincial, y posterior cuantificación de las diferentes jurisdicciones que aparecen mencionadas en la matrícula de causas más numerosa, esto es, la correspondiente al año 1788 (tabla II).

TABLA II. DISTRIBUCIÓN GEOGRÁFICA DE CAUSAS CRIMINALES EN 1788.

\begin{tabular}{|l|r|r|}
\hline Provincias & $\mathrm{N}^{\mathrm{o}}$ & $\%$ \\
\hline Santiago & 78 & 27,18 \\
\hline Ourense & 71 & 24,73 \\
\hline Lugo & 53 & 18,47 \\
\hline Betanzos & 33 & 11,50 \\
\hline Tui & 26 & 9,06 \\
\hline Coruña & 17 & 5,92 \\
\hline Mondoñedo & 9 & 3,13 \\
\hline Total & 287 & 100 \\
\hline
\end{tabular}

La primera conclusión a la que podemos llegar a partir de los resultados obtenidos es que la mayor o menor participación de las diferentes provincias en la conflictividad judicial de índole penal está directamente relacionada con el volumen de su población. Así lo constatamos mediante la comparación de las tasas de litigiosidad provincial con las relativas al peso demográfico de cada una de ellas dentro del Reino según los datos disponibles para 1787 (tabla III).

Las diferencias más significativas entre ambos porcentajes se detectan en el caso de Coruña, cuya sobre-criminalización se explicaría por el control que en la zona ejerce la Real Audiencia, y Mondoñedo, infra-representado en la crimi- 
nalidad atendiendo a que la importancia de sus habitantes dentro del conjunto gallego duplica su tasa de criminalidad.

\section{TABLA III. RELACIÓN ENTRE PARTICIPACIÓN EN LA LITIGIOSIDAD CRIMINAL Y PESO DEMOGRÁFICO}

\begin{tabular}{|l|c|c|}
\hline Provincias & \% Causas 1788 & \% Población 1787 \\
\hline Santiago & 27,18 & 29,58 \\
\hline Ourense & 24,73 & 21,85 \\
\hline Lugo & 18,47 & 17,32 \\
\hline Betanzos & 11,50 & 10,43 \\
\hline Tui & 9,06 & 10,78 \\
\hline Coruña & 5,92 & 3,71 \\
\hline Mondoñedo & 3,13 & 6,32 \\
\hline Total & 100 & 100 \\
\hline
\end{tabular}

TABLA IV. RELACIÓN ENTRE PARTICIPACIÓN EN LA LITIGIOSIDAD CRIMINAL Y PESO DEMOGRÁFICO

\begin{tabular}{|l|c|c|}
\hline Provincias & \% Causas 1848 & \% Población $1844{ }^{36}$ \\
\hline Coruña & 29,39 & 30,09 \\
\hline Lugo & 16,33 & 24,67 \\
\hline Ourense & 35,08 & 21,12 \\
\hline Pontevedra & 19,20 & 24,12 \\
\hline Total & 100 & 100 \\
\hline
\end{tabular}

La distribución de las transgresiones penales en el interior de Galicia parece cambiar a mediados del siglo XIX (tabla IV), ya que ahora la relación entre participación criminal y número de vecinos de cada provincia no es tan estrecha, como lo demuestra la comparación del porcentaje de la totalidad de causas tratadas por la Audiencia Territorial en $1848^{37}$ con el peso demográfico provincial en 1844 a partir de la encuesta realizada por el mismo Pascual Madoz.

36 La distribución de la población entre las cuatro provincias gallegas se ha realizado a partir de los cálculos elaborados por Madoz en 1844 una vez rectificados por el profesor Antonio EIRAS ROEL, La población de Galicia, 1700-1860. Crecimiento, distribución espacial y estructura de la población de Galicia en los siglos XVIII y XIX, Santiago de Compostela, 1996, p. 65.

37 La comparación de la relación entre participación criminal y volumen de población provincial a fines del XVIII y mediados del XIX obliga a tomar en consideración ahora el total de causas sustanciadas en la Audiencia Territorial en 1848 y no el número de delitos correspondientes a las cinco categorías anteriormente señaladas. El total de demandas criminales juzgadas en ese año asciende a 2.688 .

Hispania, LXV/2, núm. 220 (2005) 409-442 
Sin lugar a dudas, esta importante transformación tendrá que ver con los cambios experimentados por el modelo criminal en la primera mitad del ochocientos en el sentido de un progresivo aumento de los delitos contra la propiedad, lo que hace que la criminalidad dependa en mayor medida de factores económicos que demográficos. Así, Ourense, a pesar de ocupar el último lugar en lo que se refiere a la participación demográfica, se sitúa a la cabeza de la litigiosidad penal gallega, representando el $35,08 \%$ de las causas sustanciadas en la Audiencia Territorial en 1848, lo que se explica precisamente por la importancia que adquiere dentro de la delincuencia el contrabando, crimen que representa el 16,32\% del total de las ofensas juzgadas en ese año, localizándose el 55,32\% de ellos en esta provincia. Sus condiciones geográficas resultan óptimas para este tipo de ilegalidad según revela el propio Pascual Madoz:

La provincia de Orense carece de costa, pero disfruta de una estensa frontera con el reino de Portugal, sin los obstáculos que para la libre comunicación con el espresado reino ofrece el Miño a la provincia de Pontevedra; y los ásperos montes que forman sus límites favorecen al contrabandista que oculta el fraude con la mayor facilidad y huye la vigilancia de los carabineros. Sus lindes con las otras provincias de Castilla, le proporcionan segura salida a su ilícito comercio y al del mismo género que viene a él de las costas de Pontevedra y la Coruña ${ }^{38}$.

A pesar de lo reducido de la muestra para algunas provincias (caso de $\mathrm{A}$ Coruña, Tui y Mondoñedo), si analizamos los datos de la matrícula de 1788 atendiendo a la provincia de origen de las querellas (tabla V), el resultado obtenido, tomado con todas las precauciones debidas como un simple indicador,

TABLA V. DistribuCIÓN DE LAS CAUSAS POR PROVINCIAS SEGÚN EL INFORME DE 1788

\begin{tabular}{|c|c|c|c|c|c|c|c|c|c|c|c|c|c|c|}
\hline \multirow[t]{2}{*}{ Grupo Delictivo } & \multicolumn{2}{|c|}{ Santiago } & \multicolumn{2}{|c|}{ Betanzos } & \multicolumn{2}{|c|}{ Coruña } & \multicolumn{2}{|c|}{ Tui } & \multicolumn{2}{|c|}{ Mondoñedo } & \multicolumn{2}{|c|}{ Lugo } & \multicolumn{2}{|c|}{ Ourense } \\
\hline & $\mathrm{N}^{\circ}$ & $\%$ & $\mathrm{~N}^{\circ}$ & $\%$ & $\mathrm{~N}^{\circ}$ & $\%$ & $\mathrm{~N}^{\circ}$ & $\%$ & $\mathrm{~N}^{\circ}$ & $\%$ & $\mathrm{~N}^{\circ}$ & $\%$ & $\mathrm{~N}^{\circ}$ & $\%$ \\
\hline Muertes & 21 & 26,9 & 10 & 30,3 & 4 & 23,5 & 3 & 11,5 & 1 & 11,1 & 7 & 13,2 & 13 & 18,3 \\
\hline Robos & 20 & 25,6 & 8 & 24,2 & 6 & 35,3 & 10 & 38,5 & 2 & 22,2 & 17 & 32,1 & 14 & 19,7 \\
\hline Maltrato & 13 & 16,7 & 8 & 24,2 & 3 & 17,6 . & 4 & 15,4 & 4 & 44,4 & 14 & 26,4 & 18 & 25,3 \\
\hline Amancebamiento & 8 & 10,2 & 3 & 9,1 & 1 & 5,9 & 6 & 23,1 & 1 & 11,1 & 10 & 18,9 & 17 & 23,9 \\
\hline Causas Comunes & 16 & 20,5 & 4 & 12,1 & 3 & 17,6 & 3 & 11,5 & 1 & 11,1 & 5 & 9,4 & 9 & 12,7 \\
\hline Total & 78 & 100 & 33 & 100 & 17 & 100 & 26 & 100 & 9 & 100 & 53 & 100 & 71 & 100 \\
\hline
\end{tabular}

revela que las siete circunscripciones territoriales gallegas de fines del setecientos se adecuan al paradigma criminal diseñado para el conjunto del Reino: predominio de los atentados contra la persona seguidos de los ejecutados contra la

38 MADOZ, P.: Diccionario geográfico-estadístico..., opus.cit., vol.II, p. 354. 
propiedad. La nota discordante es Tui, en donde la situación se invierte y los robos, con un $38,46 \%$ superan a muertes y malos tratos $(26,92 \%)$, lo que se relaciona con la proximidad de esta provincia al reino de Portugal, en donde se refugiarían buena parte de los bandoleros que en los años finales del XVIII y sobre todo en la primera mitad del XIX actúan agavillados por toda Galicia ${ }^{39}$.

El estudio comparativo de las tasas delictivas de las cuatro provincias atlánticas y de las tres del interior (tabla VI) permite observar la existencia de dos modelos diferenciados de criminalidad que deben de ser puestos en relación con las dos diferentes realidades demográfico-económicas y, en consecuencia, sociales, que genéricamente podemos distinguir en la Galicia del siglo XVIII ${ }^{40}$. Por un lado tenemos la Galicia occidental (correspondiente, grosso modo, a las provincias de Coruña, Betanzos, Santiago y Tui), en donde se concentra el $55 \%$ de la población gallega a mediados de la centuria, con altas densidades de población gracias a la temprana introducción del maíz, familias de tamaño medio, fuerte emigración masculina, un sistema de transmisión patrimonial flexible que lleva a una progresiva subdivisión de la tierra y a la constitución de nuevos hogares, en la que tienen lugar transformaciones agrarias sustanciales que permiten el paulatino desarrollo del sistema agrícola de carácter intensivo combinado con una ganadería estabulada orientada a la producción de ganado vacuno y porcino. Por otro lado, la Galicia oriental (provincias de Mondoñedo, Lugo y Ourense) con densidades de población bajas y medias, predominio de familias complejas, en donde se constata — según zonastanto la emigración de ambos sexos como la ausencia de emigración, en la que la transmisión patrimonial es más rígida puesto que se suele practicar la mellora de uno de los hijos sobre los demás y cuya agricultura permanece al margen de las transformaciones agrarias hasta bien avanzado el siglo XVIII estando definida por el carácter elemental de las rotaciones, los bajos rendimientos por hectárea, el predominio de una ganadería extensiva, la importancia de lo inculto y las explotaciones de tamaño medio superior a las dos hectáreas.

\section{TABla VI.- Patrón Delictivo de la GaliCIa OCCIDENTAL Y ORIENTAL SEGÚN LA MATRÍCULA DE 1788}

\begin{tabular}{|l|c|c|c|c|}
\hline Grupo Delictivo & \multicolumn{2}{|c|}{ Galicia Occidental } & \multicolumn{2}{c|}{ Galicia Oriental } \\
\hline & Número & $\%$ & Número & $\%$ \\
\hline Muertes & 38 & 24,67 & 21 & 15,79 \\
\hline Robos & 44 & 28,57 & 33 & 24,81 \\
\hline Maltrato & 28 & 18,18 & 36 & 27,07 \\
\hline Amancebamiento & 18 & 11,69 & 28 & 21,05 \\
\hline Causas Comunes & 26 & 16,88 & 15 & 11,28 \\
\hline Total & 154 & 100 & 133 & 100 \\
\hline
\end{tabular}

39 LOPEZ MORAN, B.: El bandolerismo gallego en la primera mitad del siglo XIX, A Coruña, 1995.

40 SAAVedra VazQUeZ, M.C.: Galicia na Idade Moderna, A Coruña, 1995 
La Galicia occidental presenta cotas de robos mayores que la oriental $(28,57 \%$ frente a $24,81 \%$ ), lo que se relaciona tanto con el proceso de degradación de la producción agrícola que esta zona sufre en la segunda mitad del XVIII ${ }^{41}$ (situación que impulsaría a parte de la población a hacer del hurto una actividad complementaria de su economía a fin de lograr la subsistencia ${ }^{42}$ ), como con su carácter más urbano y económicamente evolucionado (realidad que conlleva unos mayores niveles de monetarización, intercambio comercial y circulación de mercancías). Por otro lado, en las comarcas interiores del Reino las transgresiones de naturaleza sexual alcanzan unos niveles muy superiores a los constatados de media en la orla costera $(21,05 \%$ frente al $11,69 \%)$. La importancia de los delitos de la carne en la Galicia interior está en perfecta consonancia con sus más altos porcentajes de nacimientos ilegítimos y la más débil asimilación de las restricciones morales del patrón inspirado por la Iglesia en este territorio ${ }^{43}$. Finalmente, en lo que atañe a los atentados contra la persona, la participación de ambas regiones en este grupo delictivo es exactamente igual (42,85\%), pero aún así existe una diferencia fundamental entre ellas que tiene que ver con sus formas de manifestarse,

41 Entre 1682 y 1727 la Galicia occidental vive una fase de plenitud agraria en la que la producción alcanza cotas muy elevadas y la población llega a su optimum para las posibilidades de la época, al tiempo que se registran elevados valores del salario real. Entre 1728 y 1753, durante la denominada fase de apogeo precario, los índices de producción logran sus valores más altos de Antiguo Régimen y el número de habitantes también se multiplica con respecto al período anterior, pero este desarrollo se encuentra gravemente comprometido porque la población crece en mayor medida que la producción dando lugar a una larga fase de degradación y pauperización entre 1754 y 1812, período en el que se interrumpe el crecimiento de la producción agrícola, descienden los salarios y el precio del grano aumenta mientras que la población se mantiene. EIRAS ROEL, A.: «Producción y precios agrícolas en la Galicia atlántica en los siglos XVII-XVIII. Un intento de aproximación a la coyuntura agraria», en Congreso de Historia Rural. Siglos XV al XIX. Universidad Complutense de Madrid, 1984, pp. 406 a 411. En realidad este trabajo se basa en toda una serie de monografías comarcales de historia rural realizadas en la década de los setenta y ochenta por un importante número de investigadores modernistas insertados dentro de un plan de trabajo desarrollado por el Departamento de Historia Moderna de la Universidad de Santiago bajo la dirección del propio don Antonio Eiras Roel. Entre ellas cabe destacar las elaboradas por BARREIRO MALLON, B.: La jurisdicción del Xallas en el siglo XVIII. Población, sociedad y economía, Santiago de Compostela, 1977, Perez Garcia, J.M.: Un modelo de sociedad rural en el Antiguo Régimen en la Galicia costera, Santiago de Compostela ,1979 y REY CASTELAO, O.: Aproximación a la bistoria rural en la comarca de la Ulla (siglos XVII y XVIII), Santiago de Compostela, 1981.

42 La necesidad ante coyunturas económicas adversas es el factor explicativo de la tendencia al robo de quienes resultan más afectados por éstas, lo que será visible sobre todo en el siglo XVIII. BEATTIE, J.M.: "The pattern of crime in England...", opus.cit., p. 74, CASTAN, N.: Les criminels de Languedoc. Les exigences d'ordre et les voies du ressentiment dans une société pré-révolutionnaire (17501790), Toulouse, 1980, p. 218 y Weisser, M. R., Criminalità e repressione nell'Europa Moderna, Bolonia, 1989 , p. 37.

43 Según Isidro Dubert, las tasas de ilegitimidad en la orla costero occidental se situarían entre el 1,8 y el $5,5 \%$ mientras que en las comarcas interiores alcanzarían niveles entre el 5,4 y el 11,7\%.DUBERT GARCIA, I.: «Los comportamientos sexuales premaritales en la sociedad gallega del Antiguo Régimen», en Studia Histórica, IX, 1991, pp. 128-129. 
pues en la Galicia atlántica las muertes son más frecuentes tanto en términos absolutos como relativos (24,67\% frente a $15,79 \%)$, mientras que en las áreas del interior el porcentaje de injurias y lesiones reprimidas es superior al presentado en la zona occidental $(27,08 \%$ frente a $18,18 \%)$.

También a mediados del siglo XIX (tabla VII) la criminalidad de las cuatro provincias gallegas se ajusta al panorama delictivo que hemos definido para el conjunto del Reino, es decir: predominio de los crímenes contra las personas, aunque escasamente por encima de los atentados contra la propiedad debido al espectacular aumento experimentado por las causas sobre robo, y paralelo descenso en picado de la represión dirigida contra el comportamiento inmoral. La provincia que más se aleja de este esquema es Lugo, en donde la preponderancia de la violencia interpersonal es absoluta, superando en más de 27 puntos a los hurtos.

\section{TABLA VII. DISTRIBUCIÓN DE LAS CAUSAS POR PROVINCIAS SEGÚN} LA ESTADÍSTICA CRIMINAL DE 1848

\begin{tabular}{|c|c|c|c|c|c|c|c|c|}
\hline \multirow[t]{2}{*}{ Grupo Delictivo } & \multicolumn{2}{|c|}{ A Coruña } & \multicolumn{2}{|c|}{ Pontevedra } & \multicolumn{2}{|c|}{ Lugo } & \multicolumn{2}{|c|}{ Ourense } \\
\hline & $\mathrm{N}^{0}$ & $\%$ & $\mathrm{~N}^{0}$ & $\%$ & $\mathrm{~N}^{\mathrm{o}}$ & $\%$ & $\mathrm{~N}^{\mathrm{o}}$ & $\%$ \\
\hline Muertes & 53 & 8,97 & 39 & 11,30 & 43 & 11,34 & 47 & 7,74 \\
\hline Robos & 263 & 44,50 & 129 & 37,39 & 108 & 28,50 & 277 & 45,63 \\
\hline Maltrato & 193 & 32,66 & 112 & 32,46 & 169 & 44,59 & 205 & 33,77 \\
\hline Amancebamiento & 4 & 0,68 & 4 & 1,16 & 8 & 2,11 & 5 & 0,82 \\
\hline Causas Comunes & 78 & 13,18 & 61 & 17,68 & 51 & 13,46 & 73 & 12,03 \\
\hline Total & 591 & 100 & 345 & 100 & 379 & 100 & 607 & 100 \\
\hline
\end{tabular}

Las diferencias entre oriente y occidente (tabla VIII) se siguen manteniendo, de manera que el modelo criminal de la Galicia interior continúa presentando rasgos de un mayor arcaísmo.

TABLA VIII. PATRÓN DELICTIVO DE La GaLICIA OCCIDENTAL Y ORIENTAL SEGÚN LA ESTADÍSTICA DE 1848

\begin{tabular}{|l|c|c|c|c|}
\hline Grupo Delictivo & \multicolumn{2}{|c|}{ Galicia Occidental } & \multicolumn{2}{c|}{ Galicia Oriental } \\
\hline & Número & $\%$ & Número & $\%$ \\
\hline Muertes & 92 & 9,83 & 90 & 9,13 \\
\hline Robos & 392 & 41,88 & 385 & 39,05 \\
\hline Maltrato & 305 & 32,58 & 374 & 37,93 \\
\hline Amancebamiento & 8 & 0,85 & 13 & 1,32 \\
\hline Causas Comunes & 139 & 14,85 & 124 & 12,58 \\
\hline Total & 936 & 100 & 986 & 100 \\
\hline
\end{tabular}


En la Galicia oriental, los procesos por muertes, lesiones e injurias son porcentualmente más importantes que en las provincias costeras $(47,06 \%$ frente a $42,41 \%$ ) y además la distancia que los separa de los pleitos por sustracción de bienes es más significativa ( 8 puntos). En tercer lugar, si bien se han reducido drásticamente las denuncias derivadas de desviaciones sexuales, su presencia es más fuerte que en el ámbito atlántico ( $1,35 \%$ frente a $0,85 \%)$. En éste, por el contrario, la violencia ejecutada contra el prójimo y los robos se sitúan casi en pie de igualdad ( $42,41 \%$ y $41,88 \%$ respectivamente), mientras que la represión de la variada gama de relaciones sexuales ilícitas prácticamente ha desaparecido. Finalmente, también se ha desvanecido la diferencia en cuanto a las formas adoptadas por los delitos contra la persona ya que las comarcas del interior se han adaptado al patrón que a fines del setecientos sólo estaba vigente en la Galicia occidental y que apunta hacia manifestaciones menos dramáticas de violencia, siendo partícipe así de la ya mencionada tendencia secular de declive de las tasas de homicidios.

Por supuesto, esta definición y caracterización de los arquetipos criminales existentes en el Reino de Galicia a fines del Antiguo Régimen no pasa de ser meramente indicativa en razón del reducido número de causas disponible en la muestras manejada para fines del siglo XVIII. Corresponde a futuras investigaciones más profundas y detalladas del fenómeno criminal en diferentes áreas de la geografía gallega ratificarla o desmentirla.

\section{LA CRIMINALIDAD EN LA PROVINCIA DE SANTIAGO}

El análisis que desde una perspectiva global hemos realizado de la criminalidad existente en el Reino de Galicia a finales del setecientos ha revelado que la provincia de Santiago presenta las mayores tasas de litigiosidad penal de la época: de ella provienen el $27,18 \%$ del total de querellas que llegan a ser conocidas por los jueces de la Real Audiencia. Como ya hemos señalado, esta alta cota de representación está directamente ligada a la importancia demográfica de esta provincia en el conjunto gallego, a lo que hay que añadir el mayor empleo de los tribunales por parte de los habitantes de ciudades y villas en comparación con los vecinos del campo ${ }^{44}$, siendo la provincia de Santiago la más urbanizada del Reino y contando además con la ciudad demográficamente más

44 El carácter urbano de la justicia de Antiguo Régimen ha sido puesto de manifiesto por varios autores: CASTAN, N.: Justice et repression en Languedoc à l'époque des Lumières, París, 1980, p. 25; MUCHEMBLED, R.: L'invention de l'bomme moderne. Sensibilités, moeurs et comportements collectifs sous l'Ancien Régime, París, 1988, pp.167 y ss.; DUBERT GARCIA, I.: Historia de la familia en Galicia durante la Epoca Moderna, 1550-1830: estructura, modelos bereditarios y conflictividad, A Coruña, 1992, p. 273; GONZALEZ FERNANDEZ, J.M.: La conflictividad ordinaria en la Galicia atlántica (1670-1820). Bouzas y otros juzgados gallegos en el siglo XVIII, Vigo, 1997, p. 33; IGLESIAS ESTEPA, R.: Las quiebras del orden cotidiano..., opus. cit., pp. 110-111. 
importante si exceptuamos el caso totalmente atípico de la villa de Ferrol ${ }^{45}$. Por lo tanto, un estudio más profundo del paradigma criminal de la provincia de Santiago no sólo se justifica por la elevada participación de sus habitantes en la conflictividad judicial general de naturaleza penal sino también en razón de la constatación de la existencia de modelos delictivos diferenciados para el área atlántica y para el área interior de Galicia. Su examen permite conocer grosso modo el comportamiento criminal que caracteriza a casi el $30 \%$ de los gallegos al tiempo que ofrece una imagen más detallada del patrón de delincuencia presente en la parte occidental del Reino.

Para investigar la criminalidad en este nivel provincial hemos recurrido al empleo de la documentación judicial generada por el tribunal real. Su carácter masivo y el sistema de catalogación de los fondos anteriores a 1761, fecha de creación de la sala del crimen, dificultan tanto la localización de las causas relativas al contexto geográfico y temporal que nos interesa como su posterior vaciado exhaustivo. Por ello, para el análisis de los delitos reprimidos en la provincia de Santiago a lo largo del siglo XVIII y primer tercio del XIX, hemos optado por la realización de tres estadísticas diferentes y complementarias:

1. Por un lado, hemos reunido en una única muestra los datos sobre los delitos denunciados en esta provincia entre 1700 y 1834 y que se encuentran repartidos entre cuatro series documentales: Particulares, Sala del Crimen, Vecinos y Sobreseimientos e Inbibitorias. Su volumen total asciende a 1.465 pleitos, cifra significativa que permite observar de manera general el panorama criminal en esta zona durante el último siglo del Antiguo Régimen.

2. Por otro lado, hemos tratado de observar las variaciones que a lo largo de la centuria se producen en el modelo delictivo mediante la comparación de los resultados ofrecidos por la documentación de la serie Particulares con los extraídos de la Sala del Crimen.

3. Finalmente, hemos vaciado minuciosamente la totalidad de las causas de cada uno de estos fondos referidas al siglo XVIII así como las relativas al trienio 1817-1819 de la serie correspondiente a la Sala del Crimen, lo que ha permitido obtener información detallada de 481 querellas, posibilitando la elaboración de una estadística en la que el grado de análisis es más profundo al poder diferenciar y comparar la criminalidad suscitada en el medio urbano y en el rural.

45 Ferrol experimenta un brusco crecimiento desde mediados del siglo XVIII a raíz del establecimiento de los Arsenales Reales, de manera que logra arrebatar a Compostela la primacía numérica que había mantenido durante todo el Antiguo Régimen. Sobre la evolución demográfica de la villa de Ferrol, Martin Garcia, A., Población y sociedad del Ferrol y su Tierra en el Antiguo Régimen, Santiago de Compostela, 2002.

Hispania, LXV/2, núm. 220 (2005) 409-442 
Tabla IX. Distribución deTallada de las CaUSAS dE la PRovincia de SANTIAgo. 1700-1834

\begin{tabular}{|c|c|c|c|}
\hline Grupo Delictivo & Tipo de Delito & $\mathrm{N}^{\circ}$ Causas & $\%$ Causas \\
\hline \multirow{7}{*}{$\begin{array}{l}\text { Contra la } \\
\text { Persona }\end{array}$} & Muertes & 207 & 14,13 \\
\hline & Lesiones & 418 & 28,53 \\
\hline & Injurias & 162 & 11,06 \\
\hline & Injurias/lesiones & 16 & 1,09 \\
\hline & Violación & 2 & 0,14 \\
\hline & Rapto con fuerza & 3 & 0,20 \\
\hline & TOTAL & 808 & 55,15 \\
\hline \multirow{4}{*}{$\begin{array}{l}\text { Contra la } \\
\text { Propiedad }\end{array}$} & Hurto-Robo & 343 & 23,41 \\
\hline & Destrucción de bienes & 34 & 2,32 \\
\hline & Hurto con falsedad & 5 & 0,34 \\
\hline & TOTAL & 382 & 26,07 \\
\hline \multirow{7}{*}{$\begin{array}{l}\text { Contra el } \\
\text { Orden Público }\end{array}$} & Mala conducta & 17 & 1,16 \\
\hline & Vagancia & 12 & 0,82 \\
\hline & Fuga cárcel & 25 & 1,71 \\
\hline & Resistencia a la Justicia & 41 & 2,80 \\
\hline & Conmociones populares & 10 & 0,68 \\
\hline & Armas prohibidas & 3 & 0,20 \\
\hline & TOTAL & 108 & 7,37 \\
\hline \multirow{3}{*}{$\begin{array}{l}\text { Contra la } \\
\text { Moral Sexual }\end{array}$} & Estupro & 23 & 1,57 \\
\hline & Andar maldivertido & 82 & 5,60 \\
\hline & TOTAL & 105 & 7,17 \\
\hline \multirow{2}{*}{$\begin{array}{l}\text { Excesos de los } \\
\text { Oficiales de Justicia }\end{array}$} & Excesos & 21 & 1,43 \\
\hline & TOTAL & 21 & 1,43 \\
\hline \multirow{5}{*}{ Varios } & Falsedades & 10 & 0,68 \\
\hline & Contrabando & 1 & 0,07 \\
\hline & Desaparición & 4 & 0,27 \\
\hline & Sin Especificar & 26 & 1,77 \\
\hline & TOTAL & 41 & 2,80 \\
\hline TOTALES & & 1465 & 100 \\
\hline
\end{tabular}

El panorama delictivo revelado por los pleitos criminales procedentes de la provincia de Santiago juzgados en la Real Audiencia coincide grosso modo con los resultados generales que sobre dicha circunscripción se han logrado a partir del informe de causas pendientes y sustanciadas en 1788 , lo que redunda en la validez de esa fuente cuando lo que se pretende es no ir más allá de la obtención de una visión global de la criminalidad del Reino de Galicia en un mo- 
mento dado. Como es lógico, un análisis más profundo de las ofensas denunciadas y reprimidas a partir de una muestra más numerosa y referida a un período de tiempo prolongado nos permite obtener una imagen más detallada del comportamiento criminal de la población.

Según los datos recogidos en la tabla IX, los atentados contra la persona representan el 55,15\% del total de querellas que desde la provincia de Santiago llegan a conocimiento del tribunal supremo gallego entre 1700 y 1834 , lo que supone una presencia mayor que la indicada por la matrícula de 1788 para el mismo territorio $(43,59 \%)$. Además, la distribución interna de las infracciones que integran este grupo delictivo permite observar que, contrariamente a lo que indicaba este informe, los homicidios no ocupan el primer puesto en lo que respecta a la violencia interpersonal, si bien su presencia sigue siendo significativa no sólo dentro de esta categoría criminal, en la que uno de cada cuatro litigios hacen referencia a muertes $(25,62 \%)$, sino también en lo que atañe al conjunto de la criminalidad puesto que con su $14,13 \%$ se sitúan en tercer lugar en el ranking general de la provincia. En realidad, en la mayoría de las ocasiones la muerte no es premeditada sino la consecuencia final de riñas y pendencias entre iguales que terminan mal. Así, los malos tratos de obra ejercidos contra el prójimo son porcentualmente más numerosos que los de palabra ( $51,73 \%$ frente a $20,05 \%$ de insultos e injurias), erigiéndose las lesiones como la principal acción criminal de la época $(28,53 \%$ del total de causas).

Los crímenes que tienen por objeto la propiedad ocupan el segundo puesto en la jerarquía delictiva de la provincia de Santiago, suponiendo el 26,07\% de las demandas. Esta tasa es bastante similar a la señalada para el mismo espacio geográfico en el informe de $1788(25,64 \%)$ y, en cualquier caso se sitúa muy por debajo de la de los procesos suscitados a partir de agresiones contra la integridad física y/o el honor de las personas. Se trata de una categoría que está constituida casi exclusivamente por hurtos y robos, ya que los pleitos por destrucción de bienes son escasos, representando tan sólo el 8,9\% del total de su grupo, mientras que las formas más astutas de delincuencia contra el patrimonio, como por ejemplo el hurto con falsedad, apenas están presentes $(1,31 \%)$.

El 7,17\% de los litigios que desde las distintas jurisdicciones de la provincia de Santiago llegan a la Real Audiencia hace referencia a comportamientos contrarios a la moral sexual. Generalmente se refieren a juicios contra maldivertidos, término polisignificativo que agrupa situaciones variopintas pero mayoritariamente relativas al trato ilícito entre jóvenes antes de casarse o a amancebamientos prolongados. Este porcentaje es inferior al obtenido a partir de la matrícula de causas originarias de la provincia de Santiago y que han sido sustanciadas o todavía están pendientes en el tribunal regio coruñés en 1788 (10,2\%), pero aún así sigue ocupando un puesto destacado dentro de la criminalidad general, casi en pie de igualdad con los delitos de contravención del orden público.

El resto de causas conocidas por los alcaldes mayores del Reino representan el $11,61 \%$ del total. Vendrían a equipararse con el epígrafe de «causas comu- 
nes» diferenciado por los escribanos de la sala del crimen en los informes remitidos al Consejo de Castilla y que en 1788 ascendía, en el caso de la provincia de Santiago, al 20,51\% de las demandas. El análisis detallado a partir de la documentación judicial de la Real Audiencia permite conocer el tema genérico al que hacen referencia, de manera que observamos que en su mayoría atañen a ofensas al orden público, epígrafe en el que se integrarían el 7,37\% del total de expedientes. Los diferentes apartados de esta categoría se agrupan en problemas relacionados con la impartición de justicia, tumultos y conductas contrarias a la tranquilidad social.

La tabla IX nos ofrece una imagen estática del panorama delictivo global en el período final del Antiguo Régimen, pero en tanto que fenómeno histórico, el investigador de la criminalidad también debe de preocuparse por observarla a lo largo del tiempo con el fin de detectar los cambios y permanencias. En este sentido, los fondos judiciales consultados sólo revelan de forma genérica la evolución experimentada a lo largo del siglo por las infracciones penales denunciadas ante los diferentes tribunales de la provincia, pues su estudio debe reducirse a la comparación del patrón criminal registrado en el fondo de Particulares (cuya cronología abarca de 1700 a 1760) con el extraído a partir de la información contenida en la serie de la Sala del Crimen (entre 1776 y 1819). Esto es así porque las características de la serie Vecinos, en la que únicamente se tratan los pleitos de índole penal que de oficio fueron promovidos por las diferentes justicias con facultades jurisdiccionales en esta provincia, y del fondo Sobreseimientos e Inhibitorias, referido a aquellas causas que se consideraban de escasa importancia o que suscitaban problemas de competencias entre distintas instancias judiciales, hace que los procesos contenidos en ambos conjuntos documentales no resulten representativos de la criminalidad ordinaria. Frente a ellos, las series Particulares y Sala del Crimen hacen referencia a períodos cronológicos consecutivos y dan cuenta de la litigiosidad entablada tanto por los individuos como por la propia justicia para acabar con aquellos comportamientos «desviados» que por diversos motivos les resultaban dañinos.

A partir de la información recogida en la tabla $\mathrm{X}$, observamos que la actividad judicial de la Real Audiencia en materia criminal aumenta significativamente durante la segunda mitad del siglo XVIII al experimentar el volumen total de causas generadas en la provincia de Santiago un crecimiento del $230,49 \%$, lo que coincide con la ya señalada fase de degradación de la coyuntura agraria de la Galicia atlántica. En este sentido, la tendencia registrada por la litigiosidad penal no difiere en absoluto de la evolución coyuntural relativa a la conflictividad judicial de índole civil ${ }^{46}$, recorriendo ambas un camino inverso

46 En sus estudios sobre la conflictividad familiar, Isidro Dubert ha constatado que los beneficios económicos y demográficos que resultan del cultivo del maíz hacen que entre 1690 y 1730 el nivel de reclamaciones ante los juzgados sea bajo, iniciándose en lós años siguientes, a medida que estos beneficios se agotan, un despegue que eclosionará tras 1750 y que explica las altas cotas a las que llega la apertura de expedientes ante los tribunales durante la fase 1760/90. DUBERT GARCIA,

Hispania, LXV/2, núm. 220 (2005) 409-442 
al expresado por el binomio producción/población, de modo que en las fases de bonanza económica el recurso a los tribunales de justicia para resolver las disputas protagonizadas por los vecinos de la comunidad es menor que en los períodos económicamente negativos, durante los cuales se produce un incremento de las querellas ante los juzgados. Así, en coyunturas económicas críticas, la mayor competencia entre los grupos sociales por la explotación de los recursos y el aprovechamiento de los derechos de uso conlleva la desestabilización de las lealtades personales tradicionalmente existentes en los distintos estamentos de la sociedad, lo que redunda, si no en una intensificación de la delincuencia, sí al menos en un alza del numero de denuncias interpuestas ante la justicia ${ }^{47}$.

En la Galicia atlántica, el contexto de pauperización generalizada que se vive desde mediados del setecientos lógicamente implica una reducción de los niveles habituales de tolerancia de la comunidad hacia los comportamientos «desviados», al tiempo que la progresiva monetarización de la vida económica facilita el acceso a las instancias de justicia locales, señoriales y reales, pues la mayor circulación de numerario permite afrontar los gastos que se derivan de su utilización. Por otra parte, aunque estrechamente relacionado con lo anterior, el estancamiento de la producción agrícola, el ascenso continuado de los precios del grano y el descenso incesante de los salarios ${ }^{48}$ impulsa a una parte de la población a recurrir a prácticas ilegales para subsistir, de ahí, el aumento en más de once puntos de los delitos ejecutados contra la propiedad, especialmente los hurtos y robos. En el campo, los efectos negativos de la crisis agraria llevaron a los labradores con baja capacidad económica a emplearse de forma creciente en la roturación de montes y tierras comunales con el fin de extender

I.: Historia de la familia en Galicia..., opus.cit., p. 270. Por su parte, Juan Miguel González Fernández también ha verificado en sus investigaciones sobre la conflictividad civil que la evolución diseñada por la litigiosidad de la Galicia atlántica en el XVIII coincide bastante bien con la marcha secular de la coyuntura agraria. En la fase de plenitud y «apogeo precario», es decir, entre 1682 y 1753, el nivel de pleitos es bajo mientras que a partir de 1754 y hasta 1800 se acentúa la interposición de demandas en consonancia con esa fase de degradación y pauperización generalizada. GONZALEZ FERNANDEZ, J.M.: La conflictividad ordinaria en la Galicia atlántica..., opus.cit., pp. 21-31.

47 Es la inestabilidad económica y social lo que provoca el alza de la litigiosidad y la criminalidad en una sociedad determinada. En este sentido, la tendencia registrada en Galicia coincide con la de Cantabria, en donde la rudeza de las condiciones soportadas por la economía campesina durante la segunda mitad del XVIII conllevó el aumento del número de procesos criminales. MANTECON MOVELLAN, T.A.: "Meaning and social context of crime in preindustrial times: rural society in the North of Spain, 17 th and 18th centuries", en Crime, Histoire et Societés, vol. $2, \mathrm{n}^{\circ} 1,1998$, p.60 y ss. El ejemplo contrario to tenemos en Massachusetts, cuyo porcentaje de criminalidad se mantiene más bien bajo en los siglos XVII y XVIII debido a que la homogeneidad étnica, la baja densidad de población, la gran disponibilidad de recursos, la ausencia de pobreza, etc. aseguraban la estabilidad social y un alto nivel de vida. FlaHERTY, D.: «Criminalità e controllo sociale nella provincia del Massachusetts (1639-1770)» en Cheiron. Materiali e strumenti di aggiornamento storiografico, $\mathrm{n}^{\circ} 1,1983$, pp. 129-149.

48 EIRAS Roel, A.: «Producción y precios agrícolas en la Galicia atlántica...», opus.cit., p. 409.

Hispania, LXV/2, núm. 220 (2005) 409-442 
la producción. La participación en este proceso no fue igualitaria y conllevó, por un lado, la criminalización de prácticas de uso tradicionales para los campesinos y, por otro, el desarrollo de acciones encaminadas a la destrucción de los bienes de aquellos que pretendían beneficiarse en mayor medida que sus vecinos de la privatización ${ }^{49}$, lo que fue interpretado por la historiografía marxista como la primera forma de protesta social contra los abusos de la elite propietaria $^{50}$. Su escasa presencia dentro del panorama delictivo ofrecido por la

49 El proceso de privatización de montes y comunales por parte de aquellos que gozaban de una posición opulenta dentro de la comunidad fue sentido como una agresión a los derechos «consuetudinarios» del campesinado. CONGOST, R: «Pratiques judiciaires, droits de propiété et attitudes de classe. L'exemple catalan au XVIIIe siècle» en Etudes Rurales, nº149-150, 1999, pp. 75-97. La respuesta a estas usurpaciones ilícitas en Cantabria provocó la intensificación de acciones comunitarias contra los cercadores desde mediados del XVIII. MANTECON MOVELLAN, T.A.: «Desviación, disciplina social e intervenciones judiciales en el Antiguo Régimen", en Studia Histórica, $\mathrm{n}^{\circ}$ 14, 1995 , p.239. Sobre la conflictividad generada en torno al proceso de privatización del aprovechamiento de montes y comunales en Galicia, REY CASTELAO, O.: Montes y política forestal en la Galicia del Antiguo Régimen, Santiago de Compostela, 1995. En Italia será precisamente el proceso de progresiva privatización de las tierras y la consiguiente pérdida de los usos colectivos lo que explique el auge de la delincuencia rural. SBriccol, M.: «Il furto campestre nell'Italia mezzadrile: Un'interpretazione» en Annali dell'Istituto "Alcide Cervi», 1980/2, pp. 371-378. En el caso de la provincia de Salerno a fines del XVIII la respuesta campesina adquirirá forma organizada en comitivas armada. PANICO, G., «Criminali e peccatori in Principato Citra alla fine del Setecento (17701780)», en BerLinguer, L. (ed.): Criminalità e società in età moderna. La Leopoldina, $\mathrm{n}^{\circ} 12$, Milán, 1991, pp. 549-580. En Francia e Inglaterra, el uso industrial de montes hasta entonces comunes hará que la antigua práctica de utilización de residuos con fines energéticos se criminalice y persiga intensamente en el setecientos. HILAIRE-Perez. L.: «Le vol de dechets dans l'industrie en France et en Angleterre au XVIIle siècle. Jalons pour une histoire comparée de l'Embezziement» en GARNOT, B. (dir.): La petite délinquance du Moyen Age à l'époque contemporaine, Dijon, 1998, pp. 281-308.

so En Inglaterra, E. P. Thompson y otros seguidores de la teoría marxista del conflicto de clases crearon y desarrollaron la nebulosa noción de «crimen social»: ofensa que aún estando sujeta a una sanción legal goza de un amplio grado de aceptación por parte de la comunidad en tanto que supone la defensa de sus derechos y costumbres tradicionales. Desde esta óptica, la máxima expresión del crimen social en el siglo XVIII es la destrucción de los bienes pertenecientes la elite propietaria por parte del campesinado, la cual es considerada como precursora de la protesta de trabajo en época industrial. CHAPMAN, T. L.: "Crime in Eighteenth century England: E.P. Thompson and the conflict theory of crime» en Criminal Justice History. An International Annual, vol.I, 1980, pp. 139155. En la década de los noventa la tesis del «crimen social» ha sido puesta en tela de juicio atendiendo, entre otras razones, a que dicho concepto se presta a múltiples interpretaciones, a que muchos de los atentados contra el patrimonio tenían por objeto a campesinos de la propia comunidad de convivencia -lo que demuestra la inexistencia de una solidaridad de clase- y a la constatación de que algunos trataron de utilizar sus derechos tradicionales de forma comercial (venta de leña, etc.). Una revisión crítica de dicha teoría en SHARPE, J. A.: "The history of crime in England c. 13001914. An overview of recent publications" en British Journal of Criminology, vol.28, $\mathrm{n}^{\circ} 2,1988$, p.128; OBERWITTLER, D.: «Crime and authority in Eighteenth Century England. Law enforcement on the local level» en Historical social Research, vol.15, $\mathrm{n}^{\circ} 2$ 2, 1990, p. 5 y EMSLEY, C.: «Crime and criminal justice in the European countryside: some questions for comparison» en Criminal Justice History. An International Annual, vol.XIV, 1993, pp. 2-5. 
documentación judicial de carácter criminal se debe a que estas actuaciones también podían ser tratadas civilmente, de manera que la mayoría de ellas no llegaron a la sala del crimen, de ahí que su porcentaje resulte superior en la primera mitad de la centuria, cuyos datos han sido extraídos del fondo Particulares - en donde se mezclan pleitos civiles y penales- que en la segunda.

Finalmente, este clima de desestabilización económica y social suscita un mayor celo represivo por parte de las autoridades, quienes tendrán como foco de atención prioritario la propiedad aunque también toda una serie de actitudes individuales que atentan contra el orden social instituido y que genéricamente hemos agrupado bajo el epígrafe de "delitos contra el orden público», cuya proporción aumenta en casi ocho puntos entre la primera mitad del siglo y la segunda $(0,82 \%$ frente a $8,61 \%)$.

Los cambios en las pautas de la criminalidad de la provincia de Santiago a lo largo del período objeto de estudio también afectaron a la categoría de los delitos contra la persona y a los comportamientos inmorales. En este último caso, el espectacular descenso de los pleitos que tienen por tema las relaciones sexuales ilícitas $(15,04 \%$ frente a $5,04 \%)$ remite a las ya citadas alteraciones en la mentalidad popular de fines del Antiguo Régimen en un sentido de mayor tolerancia respecto de las relaciones carnales extra y prematrimoniales, lo que conlleva una abrupta caída de las denuncias a pesar de la tendencia al alza de las tasas de ilegitimidad en un contexto económicamente adverso como es el de la Galicia atlántica de fines del Antiguo Régimen ${ }^{51}$.

51 Los estudios realizados sobre diferentes localidades y comarcas gallegas han constatado con mayor o menor intensidad el incremento de la ilegitimidad desde fines del setecientos, de manera que a mediados del XIX las concepciones de hijos naturales se convierten en un factor fundamental a la hora de explicar los movimientos vegetativos de la población. Así, en la comarca rural da Ulla, próxima a Santiago, la tasa de ilegítimos pasa del 2,97 en $1700 / 49$ al 3,02\% en $1750 / 99$ y al $6,37 \%$ en 1800/49. ReY CASTELAO, O.: Aproximación a la bistoria rural..., opus.cit., p. 42. En la península do Salnés la proporción se situaba alrededor del $4 \%$ en $1700 / 49$ y en $1750 / 99$ oscila entre el $5 \%$ y el $8 \%$, dependiendo de la parroquia. PEREZ GARCIA, J.M.: Un modelo de sociedad rural..., opus.cit., tabla 4.9 del apéndice gráfico. En Compostela el porcentaje de ilegítimos en la década $1701 / 10$ es del $3,66 \%$, en $1751-1760$ sube al $4,06 \%$, en $1791 / 1800$ crece hasta el $6,67 \%$, en 1831 1840 llega al 10,27\% y en 1861/65 alcanzar el máximo de 16,45\%. MARTINEZ RodRIGUEZ, E.: Demografía bistórica del Antiguo Régimen en la ciudad de Santiago de Compostela. Estudio de demografía urbana tradicional, Santiago de Compostela, 2002, vol.I, pp.321 y 322. No es algo exclusivo de la Galicia occidental sino que también se constata en las provincias orientales. SAAVEDRA, P.: La Galicia del Antiguo Régimen. Economía y sociedad. A Coruña, 1991, pp. 222-223. También en Madrid el gradual deterioro de las condiciones de vida de las clases populares, compuestas fundamentalmente por inmigrantes, unido al alza de los precios de la vivienda tanto en propiedad como en alquiler provocó que muchas parejas humildes decidiesen vivir amancebadas, pero al contrario de lo que sucede en Galicia, el número de procesos por crímenes contra la moralidad aumentó de forma espectacular debido al celo de la justicia, la cual en ningún caso pudo erradicar por completo estas actitudes inmorales. ALLOZA APARICIO, A.: La vara quebrada de la justicia. Un estudio bistórico sobre la delincuencia madrileña entre los siglos XVI y XVIII, Madrid, 2000, pp. 204-206.

Hispania, LXV/2, núm. 220 (2005) 409-442 
En cuanto a la violencia interpersonal, aunque sigue ocupando el primer puesto en la jerarquía de los procesos criminales, experimenta un importante retroceso, pasando del $62,60 \%$ al $52,52 \%$. Este descenso afectó tanto a las agresiones físicas como a las verbales, pero contrariamente a lo que demostraba la comparación de los datos del informe de causas pendientes del año 1788 y los relativos a la estadística de Madoz de 1848 para el conjunto del Reino de Galicia, no se constata aquí una paralela caída de las querellas por homicidio, lo que contradice la teoría de su progresivo declive secular en Europa desde la Edad Media. En realidad, consideramos que en lo que atañe a los litigios por muerte, la información de la serie Particulares y la procedente de la Sala del Crimen no es comparable puesto que, mientras que las justicias oficiales estaban obligadas a abrir una investigación de oficio cada vez que se producía una muerte ${ }^{52}$, incluso en los casos en que ésta era accidental o voluntaria (suicidio), los parientes de la víctima rara vez llegaban a los tribunales al ser conscientes de que en la mayoría de las ocasiones la muerte no era premeditada sino el trágico desenlace de excesos en las agresiones físicas que la medicina de la época era incapaz de atajar, de ahí que el número de procesos por muerte en la serie Particulares sea muy reducido. En consecuencia, el espectacular aumento experimentado por los homicidios en los dos períodos que estamos contrastando es ficticio, si bien es cierto que en las primeras décadas del XIX se produce un crecimiento del porcentaje de muertes tal y como demuestra la comparación de su tasa en 1776/1800 y en 1817/1819: 8,43\% frente a $21,74 \%$, lo que se explica en razón de un factor distorsionador como es la Guerra de Independencia contra los franceses y el ambiente conflictivo de posguerra coincidiendo con el reinado de Fernando VII ${ }^{53}$.

Por lo tanto, el examen de la evolución de la criminalidad de la provincia de Santiago durante estos dos períodos ratifica la tendencia general observada en el Reino de Galicia a través del contraste de los resultados del informe de 1788 con la estadística elaborada por Pascual Madoz en 1848 y que grosso modo se resume en tres procesos complementarios: descenso de las tasas de violencia interpersonal, aumento de los pleitos suscitados por delitos contra la

52 Ya en el Fuero Real, concedido por Alfonso X, se establecía que los alcaldes actuasen de oficio en los crímenes penados con la muerte de su autor cuando quien realizase la denuncia no conociese su identidad. La legislación posterior amplió progresivamente los casos en los que los jueces debían conocer de oficio, de manera que aunque existiese parte acusadora y se supiese quién era el culpable, la simple iniciación de oficio del juez casi puede decirse que fue la regla en la Edad Moderna. Alonso Romero, M.P.: El proceso penal en Castilla (XIII-XVIII), Salamanca, 1982., pp. 187 y 188. Así pues, cualquier muerte daba lugar a procesos de oficio, lo que explica su abundancia en los fondos de la sala del crimen, mientras que en la sección Particulares son poco numerosas por esta misma razón.

53 En Cantabria también se constata un repunte de las cifras de homicidios entre 1810 y 1830 , lo que se explica dentro el marco conflictivo posterior a la invasión francesa. MANTECON MOVELLAN, T.A.: «El poder de la violencia en el norte de España. La Cantabria rural en la Época Moderna», en I encuentro de Historia de Cantabria, Santander, 1999, p. 811. 
propiedad y caída de los procesos en los que se juzgan actitudes inmorales en materia sexual.

TABLA X. Distribución de las CaUSAS DE LA PROVINCIA DE SANTIAGo Y SU EVOlUCIÓN

\begin{tabular}{|c|c|c|c|c|c|}
\hline \multirow[t]{2}{*}{ Grupo Delictivo } & \multirow[t]{2}{*}{ Tipo de Delito } & \multicolumn{2}{|c|}{$1700-1760$} & \multicolumn{2}{|c|}{ 1776-1819 } \\
\hline & & $\mathrm{N}^{0}$ & $\%$ & $\mathrm{~N}^{0}$ & $\%$ \\
\hline \multirow{7}{*}{$\begin{array}{l}\text { Contra la } \\
\text { Persona }\end{array}$} & Muertes & 2 & 0,81 & 158 & 19,43 \\
\hline & Lesiones & 87 & 35,36 & 223 & 27,43 \\
\hline & Injurias & 48 & 19,51 & 43 & 5,29 \\
\hline & Injurias/lesiones & 16 & 6,50 & 0 & 0 \\
\hline & \begin{tabular}{|l|} 
Violación \\
\end{tabular} & 1 & 0,41 & 1 & 0,12 \\
\hline & Rapto con fuerza & - & - & 2 & 0,25 \\
\hline & TOTAL & 154 & 62,60 & 427 & 52,52 \\
\hline \multirow{4}{*}{$\begin{array}{l}\text { Contra la } \\
\text { Propiedad }\end{array}$} & Hurto-Robo & 31 & 12,60 & 225 & 27,67 \\
\hline & Destrucción de bienes & 13 & 5,28 & 12 & 1,48 \\
\hline & Hurto con falsedad & 1 & 0,41 & 4 & 0,49 \\
\hline & TOTAL & 45 & 18,29 & 241 & 29,64 \\
\hline \multirow{7}{*}{$\begin{array}{l}\text { Contra el } \\
\text { Orden Público }\end{array}$} & Mala conducta & 1 & 0,41 & 14 & 1,72 \\
\hline & Vagancia & - & - & 9 & 1,11 \\
\hline & Fuga cárcel & 1 & 0,41 & 18 & 2,21 \\
\hline & Resistencia a Justicia & - & - & 19 & 2,34 \\
\hline & Conmoción popular & - & - & 8 & 0,98 \\
\hline & Armas prohibidas & - & - & 2 & 0,25 \\
\hline & TOTAL & 2 & 0,82 & 70 & 8,61 \\
\hline \multirow{3}{*}{$\begin{array}{l}\text { Contra la } \\
\text { Moral Sexual }\end{array}$} & Estupro & 22 & 8,94 & 1 & 0,12 \\
\hline & Andar maldivertido & 15 & 6,10 & 40 & 4,92 \\
\hline & TOTAL & 37 & 15,04 & 41 & 5,04 \\
\hline \multirow{2}{*}{$\begin{array}{l}\text { Excesos de los } \\
\text { Oficiales de Justicia }\end{array}$} & Excesos & 7 & 2,84 & 7 & 0,86 \\
\hline & TOTAL & 7 & 2,84 & 7 & 0,86 \\
\hline \multirow{5}{*}{ Varios } & Falsedades & 1 & 0,41 & 5 & 0,61 \\
\hline & Contrabando & - & - & 1 & 0,12 \\
\hline & Desaparición & - & - & 4 & 0,49 \\
\hline & Sin Especificar & - & - & 17 & 2,09 \\
\hline & TOTAL & 1 & 0,41 & 27 & 3,32 \\
\hline TOTALES & & 246 & 100 & 813 & 100 \\
\hline
\end{tabular}

Hispania, LXV/2, núm. 220 (2005) 409-442 
TABLA XI. DisTRIBUCIÓN DE LAS CAUSAS SEGÚN SU ORIGEN GEOGRÁFICO.

\begin{tabular}{|c|c|c|c|c|c|}
\hline Grupo Delictivo & Tipo de Delito & \multicolumn{2}{|c|}{ RURAL } & \multicolumn{2}{|c|}{ URBANO } \\
\hline & & $\mathrm{N}^{\mathrm{o}}$ & $\%$ & $\mathrm{~N}^{\circ}$ & $\%$ \\
\hline \multirow{6}{*}{$\begin{array}{l}\text { Contra la } \\
\text { Persona }\end{array}$} & Muertes & 23 & 6,70 & 9 & 6,52 \\
\hline & Lesiones & 99 & 28,86 & 29 & 21,01 \\
\hline & Injurias & 46 & 13,41 & 18 & 13,04 \\
\hline & Injurias/lesiones & 19 & 5,54 & 3 & 2,17 \\
\hline & Violación & 1 & 0,29 & 1 & 0,72 \\
\hline & TOTAL & 188 & 54,81 & 60 & 43,48 \\
\hline \multirow{4}{*}{$\begin{array}{l}\text { Contra la } \\
\text { Propiedad }\end{array}$} & Hurto-Robo & 59 & 17,20 & 37 & 26,81 \\
\hline & Destrucción de bienes & 13 & 3,79 & 4 & 2,90 \\
\hline & Hurto con falsedad & 1 & 0,29 & 1 & 0,72 \\
\hline & TOTAL & 73 & 21,28 & 42 & 30,43 \\
\hline \multirow{7}{*}{$\begin{array}{l}\text { Contra el } \\
\text { Orden Público }\end{array}$} & Mala conducta & 3 & 0,87 & 2 & 1,45 \\
\hline & Vagancia & 3 & 0,87 & 2 & 1,45 \\
\hline & Fuga cárcel & 3 & 0,87 & 5 & 3,62 \\
\hline & Resistencia a la Justicia & 4 & 1,17 & 3 & 2,17 \\
\hline & Conmociones populares & 1 & 0,29 & 1 & 0,72 \\
\hline & Armas prohibidas & - & - & 1 & 0,72 \\
\hline & TOTAL & 14 & 4,08 & 14 & 10,14 \\
\hline \multirow{3}{*}{$\begin{array}{l}\text { Contra la } \\
\text { Moral Sexual }\end{array}$} & Estupro & 20 & 5,83 & 3 & 2,17 \\
\hline & Andar maldivertido & 30 & 8,75 & 11 & 7,97 \\
\hline & TOTAL & 50 & 14,58 & 14 & 10,14 \\
\hline \multirow{2}{*}{$\begin{array}{l}\text { Excesos de los } \\
\text { Oficiales de } \\
\text { Justicia }\end{array}$} & Excesos & 16 & 4,66 & 5 & 3,62 \\
\hline & TOTAL & 16 & 4,66 & 5 & 3,62 \\
\hline \multirow{3}{*}{ Varios } & Falsedades & 一 & - & 3 & 2,17 \\
\hline & Desaparición & 2 & 0,58 & - & - \\
\hline & TOTAL & 2 & 0,58 & 3 & 2,17 \\
\hline TOTALES & & 343 & 100 & 138 & 100 \\
\hline
\end{tabular}

Las circunstancias económicas y sociales vividas por los habitantes de la provincia de Santiago son clave para explicar tanto la utilización que hacen del aparato de justicia oficial como su comportamiento criminal, de manera que éstos no sólo cambian a lo largo del tiempo, sino que también presentan variaciones según nos situemos en un contexto rural o urbano. Con el fin de conocer las diferencias y similitudes de la delincuencia en estos dos ámbitos hemos procedido a la comparación de los resultados obtenidos a partir del vaciado de 
parte de los expedientes identificados en las fichas de las distintas series consultadas ${ }^{54}$ (tabla XI).

En ambos espacios el grupo delictivo formado por los atentados contra la persona es mayoritario, si bien en el medio urbano su importancia es sensiblemente menor $(43,48 \%$ frente a $54,81 \%)$ atendiendo a que la interposición de querellas por lesiones en ciudades y villas es menos frecuente que en el campo. Observamos que el resto de indicadores de la violencia interpersonal presentan tasas bastante similares.

Las agresiones que tienen por objeto la propiedad se sitúan en el segundo puesto de la criminalidad, pero en el ámbito urbano su porcentaje resulta claramente superior, lo que se explicaría por las propias características económicas y sociales de las urbes de fines de Antiguo Régimen. Su condición de centros de comercio hace de las ciudades y villas los lugares de intercambio por excelencia, ofreciendo la circulación de mercancías y dinero mayores posibilidades de cara a la comisión de robos. Por otro lado, las urbes se erigen como núcleos receptores de la población rural que las circunda ${ }^{55}$, de manera que a ellas se trasladan numerosos individuos en busca de oportunidades vitales que no siempre encuentran. La falta de trabajo y el desarraigo en el que se ven inmersos los inmigrantes urbanos son factores que en muchas ocasiones impulsan hacia comportamientos delictivos, los cuales tendrán como forma de expresión fundamental el hurto de pequeñas proporciones ${ }^{56}$.

En el campo, los ataques a la moral sexual suscitan más procesos que en las ciudades $(14,58 \%$ frente a $10,14 \%)$ lo que demuestra no tanto la mayor inclinación de los labradores hacia los tratos ilícitos sino su mayor tendencia a denunciarlos ante las autoridades. En este sentido, las menores posibilidades de anonimato del medio rural provocaba que los tratos carnales pre o extramatrimoniales fuesen más difíciles de ocultar a los ojos de los vecinos y del párroco

54 Se han vaciado la totalidad de causas obtenidas en nuestro sondeo de la serie Particulares (246), todos los litigios de la Sala del Crimen referidos al siglo XVIII (83) y al trienio 1817/19 (92), los procesos del fondo Sobreseimientos e Inbibitorias datados en el setecientos (45) y las demandas de Vecinos de la misma cronología (15). La muestra final asciende a 481 pleitos.

ss Sobre las migraciones campo ciudad en Galicia, DuBERT GARCIA, I.: Del Campo a la ciudad. Migraciones, familia y espacio urbano en la Historia de Galicia, 1708-1924, Santiago de Compostela, 2001; MARTinez Rodriguez, E., Burgo LOPEZ, $\mathrm{M}^{2}$. C. y GonZAlez LOPO, D.: «Inmigración urbana en la Galicia del Antiguo Régimen: Santiago, Tuy y Ferrol a finales del siglo XVIII», en EIRAs Roel, A. y Rey CASTElaO, O. (eds.): Migraciones internas y medium-distance en la Península Ibérica, 1500-1900. Actas de la I Conferencia Europea de la Comisión Internacional de demografía Histórica, Santiago de Compostela, 1994, pp. 389-402.

56 La miseria económica y la falta de empleo son las causas generales de la creciente criminalidad contra la propiedad entre las clases populares del siglo XVIII a lo que hay que añadir el desarraigo familiar en el caso de los inmigrantes. Poussou, J-P.: Bordeaux et le sud-ouest au XVIIIe siècle. Croissance économique et attraction urbaine, París, 1983, p. 170 y ss.; WILLS, A.: Crime and punishment in revolutionary Paris, Londres, 1981, p. 125, HENRY, Ph.: Crime, justice et société dans la principauté de Neuchâtel au XVIIIe siècle (1701-1806), Neuchâtel, 1984, pp.519-525 y AllozA APARICIO, A.: La vara quebrada de la justicia..., opus.cit., p. 157.

Hispania, LXV/2, núm. 220 (2005) 409-442 
de la comunidad, quien tenía la obligación de denunciar estas «desviaciones» a la justicia en caso de que sus advertencias a los implicados para que rectificasen su actitud no surtiesen el efecto deseado.

Por último, en la sociedad urbana los expedientes derivados de atentados contra el orden público son proporcionalmente muy superiores a los que por los mismos tipos de delitos se generaban en las comunidades agrícolas $(10,14 \%$ frente a 4,08\%). Sin lugar a dudas, la presencia física de las autoridades judiciales en la ciudad, la concentración demográfica y un concepto distinto de orden público redundó en que el control y la represión de la vagancia, el porte de armas, la mala conducta, etc. fuese más fuerte y fácil en ella que en el escenario rural.

\section{LA CRIMINALIDAD GALLEGA EN EL CONTEXTO ESPAÑOL Y EUROPEO}

Las características del paradigma criminal gallego de finales del Antiguo Régimen nos remiten a un tipo de delincuencia tradicional en la que las ofensas referidas a la violencia interpersonal mantienen un claro predominio sobre el resto de las infracciones penales. Por lo tanto, la criminalidad constatada en el Reino de Galicia en el siglo XVIII y primer tercio del XIX está muy alejada del patrón confirmado en las grandes metrópolis europeas del momento como es el caso de París ${ }^{57}$, Londres ${ }^{58}$, Amsterdam ${ }^{59} \mathrm{o}$ Ginebra $^{60}$, en algunas de las urbes del

57 Según diferentes estudios, en el París del siglo XVIII entre el 70 y el $90 \%$ de los asuntos criminales conocidos por los jueces se referían a robos y fraudes, situación que un siglo y medio antes estaba dominada por la violencia, la cual suponía anualmente alrededor del $65 \%$ de los delitos juzgados. FARGE, A. y ZYSBERG, A.: "Les théatres de la violence...», opus.cit., p.984; LECUIR, J.: "Criminalité et «moralité»: Montyon, staticien du Parlament de Paris», en Revue d'bistoire Moderne et Contemporaine, julio-septiembre de 1974, pp. 480-482; PeTrovitch, P.: «Recherches sur la criminalité à Paris dans la seconde moitié du XVIIIe siècle», en Cabier des Annales, 33, 1971, p. 208; WILLS, A., Crime and punishment in revolutionary Paris, Londres, 1981, p. 103.

58 La preocupación que el alza de robos suscitó entre la población de Londres y de su entorno más inmediato llevó a la ampliación de la aplicación de la pena de muerte a un gran número de ofensas contra la propiedad. HAY, D.: «Property, authority and the Criminal Law», opus. cit. pp. 20-24; BEATTIE, J.M.: "Crime and the courts in Surrey 1736-1753», en COCKBURN (ed.): Crime in England 15501800, Princeton, 1977, pp. 155-186 y del mismo autor, Crime and the courts in England, Oxford, 1986.

59 En Amsterdam, el 38,2\% de las ofensas juzgadas entre 1701 y 1811 se refieren a delitos conta el patrimonio. DiederiKs, H.: «Punishment during the Ancien Regime: the case of the Eighteenthcentury Dutch republic", en KNAFLA, L.A. (ed.): Crime and criminal justice in Europe and Canada, Ontario, 1985, p. 286; «Patterns of criminality and law enforcement during the Ancien Regime: the Dutch case», Criminal Justice History. An International Annual, vol.I, 1980, pp. 157-174 y «Criminal Law and Criminal Justice in the Netherlands in the century before the codification» en BERLINNGUER, L. (ed.): Le politiche criminale nel XVIII secolo. La Leopoldina. Criminalità e giustizia criminale nelle riforme del '700 europeo, $\mathrm{n}^{\circ} 11$, Milán, 1990, pp. 359-379. Sobre la importancia de los crímenes contra el patrimonio en los Países Bajos ver también SPIERENBURG, P.: The spectacle of suffering. Executions and the evolution of repression: from a preindustrial metropolis to the European experience, Cambridge, 1984, p. 135 y ss.

60 Entre 1700 y 1792 los atentados contra la propiedad conforman la categoría delictiva más numerosa: suponen entre el 23 y el $36 \%$ de las infracciones penales. PORRET, M.: Le crime et ses 
norte de Francia ${ }^{61}$ e Italia ${ }^{62}$, en buena parte de los condados rurales de Inglaterra $^{63}$ y en las ciudades económicamente más desarrolladas del territorio español, como son los casos ya comentados de Sevilla, Barcelona y Valladolid a los que cabría añadir también Málaga ${ }^{64}$, pues en todas ellas los atentados contra la propiedad eran porcentualmente superiores a los ejecutados contra la persona.

A decir verdad, el esquema delictivo del Reino de Galicia y de la provincia de Santiago no difiere de la realidad criminal de la mayoría de las sociedades europeas dieciochescas de urbanización limitada y economía escasamente desarrolla$\mathrm{da}^{65}$. En este sentido, ni siquiera Madrid, centro de atracción de numerosos delincuentes por su condición de capital y villa cortesana, presenta en el siglo XVIII un arquetipo criminal dominado por las agresiones contra los bienes ${ }^{66}$.

circonstances. De l'esprit de l'arbitraire au siècle des Lumières selon les réquisitoires des procureurs généraux de Genève, Ginebra,1995, p. 45.

${ }_{61}$ En Lille la proporción de diligencias de la justicia por robo llega a los dos tercios mientras que en su entorno rural la brutalidad es el delito característico. DeYON, P.: Le temps des prisons. Essai sur l'bistoire de la délinquance et les origines du système pénitenciaire, París, 1975, pp. 77-79.

62 Es el caso de Florencia, en donde ya desde el siglo XV los crímenes reprimidos se refieren mayoritariamente a cuestiones de propiedad. COHN, S.K.: The laboring classes in Renaissance Florence, New York, 1980, pp.193 y 194. El mismo predominio se constata en Siena en el siglo XVIII así como en el vicariato de Prato y en Lombardía en la etapa final de éste. Di SiMPLICIO, O.: «La criminalità a Siena (1561-1808)», Quaderni Storici, n²49, XVII, fasc.I, abril 1982, p. 251; ZULIANI, D.: «Reati e pene nel Vicariato di Prato prima e dopo la Leopoldina (1781-1790)», en BERLINGUER, L. (ed.): Criminalità e società in età moderna. La Leopoldina. Criminalità e giustizia criminale nelle riforme del '700 europeo, n' ${ }^{\circ}$ 12, Milán, 1991, p. 309 y CAPRA, C. y CISERANI, M.T.: «Criminalità e repressione della criminalità in Lombardia nell 'età delle riforme: appunti per una ricerca», en BERLINGUER, $L$. (ed.): Criminalità e società in età moderna..., opus.cit. p. 1-23.

63 Las ofensas contra la propiedad suponían el $76 \%$ de las demandas en el condado de Devon en la década 1700-1709, el 80\% de las interpuestas en el condado de Cornwall entre 1700 y 1749 y el $85 \%$ de las promovidas en los condados de Norfolk y Sufforlk entre 1734 y 1737 . SHARPE, J. A.: Crime in Early modern England, 1550-1750, Londres, 1984, tabla ${ }^{\circ} 1$, p. 55.

64 Con anterioridad al siglo XVIII, la ciudad de Málaga y su comarca fueron objeto de un importante crecimiento de la criminalidad debido a la intensificación de las actividades mercantiles y al aumento de su riqueza, lo que situó a los atentados contra la propiedad en el primer lugar de la delincuencia sufrida en campo y ciudad. QUINTANA TORET, F.J.: «De los delitos y las penas. La criminalidad en Málaga y su tierra durante los siglos de oro», en Estudis, nº15, 1989, p. 245-269.

65 Es el caso de las zonas rurales de Francia, del principado de Neuchâtel en Suiza, de la Cantabria española, etc. Piegay, F.: «Delinquance et delinquants dans le baillage de Beaujolais 17431789", en GARNOT, B. (dir.): Histoire et criminalité de l'Antiquité au XXe siècle. Nouvelles approches, Dijon, 1992, pp. 181-187; DeBILLY, X.: «La petite delinquance en milieu rural au XVIII siècle: l'exemple d'Ampuis», en GaRnot, B. (dir.): La petite delinquance du Moyen Age..., opus.cit., pp.153-164; HenRY, Ph.: Crime, justice et société..., opus.cit. y MANTECON MOVEllan, T.A.: Conflictividad y disciplinamiento social en la Cantabria rural del Antiguo Régimen, Santander, 1997.

66 Entre 1755 y 1785 el 33,2\% de los crímenes cometidos en Madrid eran violentos y sólo el 17,7\% hacían referencia a la propiedad. HERNÁNDEZ SÁNCHEZ, F.: «"La corte envidiable"..., opus.cit., p.334. Según Angel Alloza, en el transcurso del XVIII, el delito contra los bienes se incrementó levemente pero siempre se mantuvo en torno a un tercio de las causas juzgadas en la Sala de Alcaldes. Será en la primera mitad del siglo XIX cuando los ataques al patrimonio experimenten

Hispania, LXV/2, núm. 220 (2005) 409-442 
Tampoco la evolución secular que la delincuencia gallega experimenta durante el setecientos y primer tercio del ochocientos diverge de la tendencia confirmada en la mayoría de los países europeos y que se caracteriza por un significativo aumento de los ataques dirigidos contra la propiedad privada. Durante algún tiempo se consideró que esta importante mutación en el comportamiento delictivo de las comunidades de fines del Antiguo Régimen suponía el paso de una criminalidad tradicional violenta a una nueva criminalidad astuta propia de las sociedades capitalistas y cuyo rasgo definitorio era el incontestable dominio de los delitos contra los bienes y la gradual desaparición de las ofensas que tenían por objeto la integridad física de las personas. Posteriores investigaciones en el campo de la historia del crimen han refutado la tesis de la modernización del modelo criminal entendida como el paso de la violencia al robo, puesto que, por un lado, se ha comprobado que el incremento del número de procesos por atentados al patrimonio es paralelo a un cambio en la actitud de las autoridades respecto de éstos en el sentido de una mayor severidad en su control y castigo, y, por otro, se ha verificado que la violencia interpersonal sigue formando parte del panorama criminal de las poblaciones económicamente avanzadas $^{67}$. En consecuencia, la mayor parte de los especialistas del fenómeno criminal son reticentes a la hora de asumir sin matizaciones que se haya producido una alteración en el patrón del crimen y apuestan más bien por afirmar que lo que ha tenido lugar es una transformación en la represión en función de los nuevos intereses de legisladores y magistrados ${ }^{68}$ de manera que

un importante crecimiento, llegando a suponer el $50 \%$ de los asuntos penales. AllozA APARICIO, A.: «La economía criminal de los desheredados. Estudio comparativo de Londres, Madrid, París y Amsterdam en el siglo XVIII y comienzos del XIX», en Revista Internacional de Sociología, $\mathrm{n}^{\circ} 23$, 1999, pp. 189-190 y La vara quebrada de la justicia..., opus.cit., pp. 156-157.

67 La violencia sigue presente en sociedades económicamente muy desarrolladas como es el caso de la industrial y capitalista ciudad de Leiden (Holanda), en donde la crisis económica sufrida en el XVIII lleva a un incremento de las agresiones físicas desde mediados de esa centuria hasta 1811. DIEDERIKS, H.: "Quality and quantity in historical research in criminality and criminal justice: the case of Leiden in teh $17^{\text {th }}$ and $18^{\text {th }}$ centuries", en Historical Social Research, vol. 15, $n^{\circ} 4,1990, .63$. A decir verdad la violencia interpersonal sigue siendo una lacra en las relaciones sociales hasta mediados del XIX sin que se pueda hablar de un cambio real en el paradigma criminal caracterizado por el paso de la violencia al robo. Se trataría más bien de una trasformación del lugar que ésta ocupa en el aparato judicial (disminución de las agresiones graves y aumento de una violencia limitada a golpes e injurias). ROUSSEAUX, X., "La violencia en las sociedades premodernas: Nivelles, una ciudad de Brabante a lo largo de cinco siglos» en ForteA, I., Gelabert, J. E. y MANTECon, T. A. (eds.): Furor et rabies. Violencia, conflicto y marginación en la Edad Moderna, Universidad de Cantabria, 2002, p. 156.

68 En este sentido Robert Muchembled advierte acerca de la propensión de los tribunales a focalizar su atención sobre cierto tipo de delitos en un determinado momento, de manera que la desaparición de algunos crímenes de los archivos represivos no quiere decir que éstos hayan desaparecido del panorama delictivo real, sino más bien el que la mirada de los hombres de la ley se dirige hacia otro punto de interés. MUCHEMBLED, R.: L'invention de l'bomme moderne... opus.cit., p.185. Así, la rarificación de la violencia en los expedientes judiciales de los tribunales de París en la segun- 
éstos, en un contexto de expansión económica de las elites sociales y de progresiva pauperización del estado llano, se preocuparían cada vez en mayor medida por las formas de delincuencia contra la propiedad y perderían interés por las expresiones de violencia, las cuales siguen existiendo pero, salvo en sus versiones especialmente graves, pasan a ser tratadas fuera de los tribunales ${ }^{69}$.

En resumen, el esquema presentado por la delincuencia que entre $1700 \mathrm{y}$ 1834 es denunciada y/o reprimida en la zona objeto de examen responde a las características definitorias de la criminalidad tradicional. Sin embargo, el análisis diacrónico de las ilegalidades penales revela un panorama criminal dinámico en lenta transición hacia la modernidad, lo que está en lógica consonancia con el proceso de desestructuración de las bases económicas, sociales y mentales que sustentaban la existencia en el Antiguo Régimen. El tenue declinar de la violencia, el progresivo avance de los atentados contra el patrimonio, el abrupto descenso de las causas por inmoralidad, la cada vez más importante presencia del contrabando, el fenómeno del bandolerismo organizado así como el mayor interés de las autoridades por sancionar los comportamientos desestabilizadores del orden público, etc. son indicadores claros del rumbo tomado por la criminalidad de la Galicia occidental, siendo los centros urbanos la avanzadilla de ese proceso de modernización.

\footnotetext{
da mitad del XVIII se explica atendiendo al poco celo del orden judicial a la hora de perseguir a los autores de agresiones de obra y palabra, ya que ahora su preocupación fundamental es la represión de los atentados contra la propiedad y el orden público. FARGE, A. y ZYSBERG, A.: «Les théatres de la violence...», opus.cit., p. 985 .

69 Recordemos que en el París dieciochesco la represión de la violencia en sus formas más banales se reserva a los comisarios. FARGE A., y ZYSBERG, A.: «Les théatres de la violence...», opus.cit., p. 986.
}

Hispania, LXV/2, núm. 220 (2005) 409-442 